ARTÍCULO

\title{
ENTRE LA VIDA PARROQUIAL Y LA MILITANCIA POLÍTICA EL ESPACIO URBANO PARA LA UNIÓN DE DAMAS CATÓLICAS, 1912-1930
}

\author{
BETWEEN PARISH LIFE AND POLITICAL MILITANCY \\ THE URBAN SPACE FOR THE UNION OF CATHOLIC LADIES, 1912-1930
}

\author{
Sofía Crespo Reyes \\ Universidad Nacional Autónoma de México \\ Facultad de Estudios Superiores-Acatlán \\ sofiacrespo@gmail.com
}

Resumen

El artículo analiza la forma en que la Unión de Damas Católicas Mexicanas (1912-1932) desarrolló su vida asociativa a partir de promover un programa de acción político-social utilizando diversas dimensiones del espacio urbano de la ciudad de México: la parroquia, la manzana, los barrios y las colonias. Igualmente, examina cómo sus acciones por la ciudad posibilitaron a la Unión construir un entramado social a través del cual actuaron en distintos campos de manera simultánea, múltiple y articulada. Así, mientras crearon un sistema catequístico, fundaron sindicatos, establecieron escuelas, instaurando una estructura material y espacial que les dio soporte para enfrentar pública y políticamente a los gobiernos posrevolucionarios. Se evalúa el papel de la parroquia como una institución fundamental en la composición y acomodo de las Damas Católicas en la estructura urbana.

Palabras clave: Unión de Damas Católicas Mexicanas, espacio urbano, parroquia, posrevolución, militancia católica.

\begin{abstract}
This paper analyzes how the Mexican League of Catholic Women (1912-1932) carried out associative activities through a program for political-social action. For that purpose, they used diverse locations of the urban space of Mexico City such as parishes, blocks and neighborhoods. The paper also examines how these activities enabled these women to build a social network around the city through which they simultaneously operated and articulated a spatial structure that supported all of their activities such as the creation of a catechetical system, catholic schools or labor unions as means for publicly and politically oppose the post-revolutionary governments. The role of the parish is examined as a fundamental institution for the organization and adaptation of these women in the urban space.
\end{abstract}

Keywords: Catholic women, urban space, parish, catholic militancy, post-revolution.

Información del artículo

Recibido: 27 de septiembre de 2019.

Aceptado: 21 de febrero de 2020.

DOI: 10.22201/iih.24485004e.2019.58.70958 


\section{Introducción}

El presente artículo centra su atención en el estudio de la organización interna de la Unión de Damas Católicas Mexicanas (UDCM) para analizar la forma en que se apropiaron del espacio público y parroquial en tres momentos: durante la Revolución Mexicana (1910-1916), a partir de la elaboración de la Constitución de 1917, en el inicio de la guerra Cristera (19171926) y durante la misma (1926-1929).

La UDCM surgió en el contexto del gobierno maderista como una agrupación social y filantrópica asociada al Partido Católico Nacional (PCN) que representaba, para la Iglesia católica y su militancia, una nueva posibilidad de participación política. ${ }^{1}$ Ellas - junto con los Caballeros de Colón ${ }^{2}$ y la Asociación Católica de la Juventud Mexicana (АСЈM) $-{ }^{3}$ fueron una de las organizaciones que años más tarde dirigieron las políticas de defensa social del catolicismo mexicano.

${ }^{1}$ Adrian A. Bantjes, "Mexican Revolutionary Anticlericalism: Concepts and Typologies”, The Americas, v. 65, n. 4, 2009, p. 467-480; Roberto Blancarte, "Closing Comment: 'Personal Enemies of God': Anticlericals and Anticlericalism in Revolutionary Mexico, 1915-1940", The Americas, v. 65, n. 4, 2009, p. 589-599; Matthew Butler, "Sotanas rojinegras: Catholic anticlericalism and México's revolutionary schism”, The Americas, v. 65, n. 4, 2019, p. 535-558).

${ }^{2}$ La Orden de los Caballeros de Colón se fundó en la ciudad de México en 1905. Su acción social abarcó el ámbito laboral y de salubridad de los trabajadores, y promovieron la formación de nuevas asociaciones independientes o complementarias a la suya, al tiempo que buscaron moralizar e instruir a los grupos marginales del país. En Ana Patricia Silva de la Rosa, Los Caballeros de Colón y su participación en el conflicto religioso de 1926 a 1929, tesis de licenciatura en Historia, México, Universidad Nacional Autónoma de México, Facultad de Filosofía y Letras, 2004, p. 17.

${ }^{3}$ La Asociación de Jóvenes Católicos de México se fundó en la ciudad de México en 1913. Este grupo comenzó como un grupo de estudiantes que aspiraban a desempeñar un papel en la vida política del país con el apoyo de dos párrocos jesuitas Bernardo Bergöend y Carlos M. Heredia. La asociación pretendía convertirse en una federación de agrupaciones católicas de jóvenes, constituida por socios, mediante círculos, centros locales y un centro general. Buscaba fomentar entre los jóvenes una identidad católica que les permitiera realizar actividades constantes y cotidianas en la vida pública del país. Para más información, véase Randall S. Hanson, The Day of Ideals: Catholic Social Action in the Age of the Mexican Revolution, 1867-1929, tesis de doctorado en Filosofía, Indiana, Universidad de Indiana, Departamento de Historia, 1994, p. 153-160; David Espinosa, "Restoring Christian Social Order. The Mexican Catholic Youth Association (1913-1932)”, The Americas, v. 59, n. 4, 2003; "Estatutos o bases generales de la Liga Nacional de Estudiantes Católicos", México, Nueva Imprenta Mariana, 1912, p. 4, en Centro de Estudios de Historia de México, Fundación Carlos Slim (сенм), fondo ClXxxLl, Impresos del Movimiento Cristero, carpeta 1, doc. 5. 
Su historia es la historia de la formación de una militancia católica femenina que comenzó a gestarse en el último tercio del siglo xIx después de que el gobierno de Sebastián Lerdo de Tejada, incorporó en septiembre de 1873, las Leyes de Reforma a la Constitución de $1857^{4}$ materializando la separación entre la Iglesia y el Estado. ${ }^{5}$ Con ello, la religión quedó reservada para la conciencia individual y la práctica interior. Ante esta nueva realidad, la Iglesia se lanzó a una lucha intransigente contra el laicismo estatal convirtiendo a sus feligreses en militantes dedicados a defender el papel moral y rector de la devoción católica en la vida pública. Esta lucha incorporó a devotas mujeres católicas quienes se dedicaron fomentar el papel tradicional de la mujer, como eje de la vida familiar, cuidadora y protectora del espacio doméstico, ama de casa, esposa y madre, "ángel del hogar".

Esta militancia católica femenina formó parte de un conjunto de iniciativas impulsadas desde la alta jerarquía eclesiástica para defender sus espacios de participación social, económica y política tradicional. ${ }^{6}$ Este proceso se hizo acompañar de una serie de esfuerzos por renovar y modificar el papel de las organizaciones piadosas como las cofradías, hermandades y organizaciones dedicadas al auxilio social y promover entre los más devotos de la sociedad un efecto de "concientización laica", 7 que permitió vincular

${ }^{4}$ Para un análisis a profundidad sobre las leyes de reforma se recomienda: Cecilia Bautista García, La disyuntiva del Estado y de la Iglesia en la consolidación del orden liberal: México, 1856-1910, México, El Colegio de México, Centro de Estudios Históricos/Fideicomiso Historia de las Américas/Universidad Michoacana de San Nicolás de Hidalgo, 2012, $424 \mathrm{p}$.

${ }^{5}$ Laura O'Dogherty Madrazo, De urnas y sotanas. El Partido Católico Nacional en Jalisco, México, Consejo Nacional para la Culturas y las Artes, 2001, p. 21.

${ }^{6}$ El surgimiento de una militancia católica dedicada a defender los intereses fue una política impulsada desde el Vaticano, sobre todo, a partir del año 1878 fecha en que León XIII asumió la cabeza del pontificado e inició una campaña de defensa de los derechos de la Iglesia a nivel internacional, que utilizaba a los católicos seglares como punta de lanza de su nueva política. Se recomienda revisar: María Luisa Aspe Armella, La formación social y política de los católicos mexicanos, México, Universidad Iberoamericana, 1993, p. 39-63.

${ }^{7}$ Matthew Butler considera que durante la guerra cristera las mujeres católicas vivieron un proceso de "concientización laica" el cuál diferenció la acción entre hombres y mujeres pertenecientes a la militancia católica. Desde mi punto de vista, este proceso de "concientización” comenzó durante el último tercio del siglo XIX y se volverá beligerante durante el conflicto cristero. Matthew Butler, “'Su hija Inés': católicas laicas, el obispo Luis María Martínez y el conflicto religioso michoacano, 1927-1929”, Historia Mexicana, El Colegio de México, México, v. LXVII, n. 3, 2018, p. 1249-1293. 
las actividades devocionales con un interés político encaminado a expandir la presencia de la Iglesia en todos los ámbitos posibles. ${ }^{8}$

Estos esfuerzos tomaron un nuevo impulso durante las primeras tres décadas del siglo xx que atestiguaron cambios radicales en diversos aspectos de la vida social, política y cultural de México, ${ }^{9}$ sobre todo, después de que Francisco I. Madero, el iniciador de la Revolución Mexicana, ganara las elecciones presidenciales y tomara posesión del cargo el 6 de noviembre de 1911. Así, la organización y el programa de trabajo de la militancia católica femenina se enfocó en defender y reforzar la autoridad y la estructura eclesiástica. Al mismo tiempo, las mujeres se convirtieron en las principales promotoras de prácticas devocionales como el Sagrado Corazón de Jesús ${ }^{10}$ y el culto a la virgen María, ${ }^{11}$ que impulsaban valores concebidos femeninos entre los que se encontraban: la sumisión, el espíritu de abnegación, el amor conyugal, la caridad, el sentimentalismo y la maternidad. Al mismo tiempo, se promovía al ámbito doméstico como el

${ }^{8}$ Sobre las organizaciones católicas que surgieron en el último tercio del siglo XIX se recomienda: Silvia Arrom, Volunteering for a Cause: Gender, Faith, and Charity in Mexico from the Reform to the Revolution, Albuquerque, University of New Mexico Press, 2016, 279 p.; Bautista, La disyuntiva del Estado y de la Iglesia..., p. 172-247; y José Alberto Moreno Chávez, Devociones políticas. Cultura católica y politización en la arquidiócesis de México 1880-1920, México, El Colegio de México, 2013, 269 p.

${ }^{9}$ Se prohibieron las prácticas públicas del culto e instrucción, la recolección de limosna y las manifestaciones religiosas fuera de los templos, las congregaciones masculinas y el reclutamiento de monjas. Con ello, la religión fue reservada para la conciencia individual y la práctica interior. Este proceso de secularización significó también la transferencia de la tutela de los individuos de la Iglesia al Estado, los individuos se convirtieron en sujetos de derecho y de esta manera se limitó el papel de la Iglesia a la esfera privada, quedando excluida de validar los nacimientos, matrimonios, defunciones, herencias, propiedades, etcétera. Para un análisis a profundidad sobre las leyes de reforma se recomienda: Bautista, La disyuntiva del Estado y de la Iglesia..., p. 100-171; Laura O’Dogherty Madrazo, "La Iglesia Católica Frente al Liberalismo", en Erika Pani (coord.), Conservadurismo y derechas en la historia de México, México, Fondo de Cultura Económica/Consejo Nacional para la Culturas y las Artes, 2009, t. 1, p. 363-391.

${ }^{10}$ Modelo devocional francés que asociaba los sufrimientos de la Iglesia (y de Cristo) como producto de la modernidad, en José Alberto Moreno Chávez, "Visiones del apocalipsis: violencia e imaginarios católicos en el México revolucionario”, en Laura Rojas y Susana Deeds (eds.), México a la luz de sus revoluciones, México, El Colegio de México, 2014, v. 2, p. 319.

${ }^{11}$ Que centraba su atención en convertir la pureza de la Virgen en un modelo de identificación para las jóvenes católicas, mismo que sería el centro de la educación femenina, en Michaela de Giorgio, "El modelo católico”, en Georges Duby y Michell Perrot, Historia de las mujeres. 4. El siglo XIX, Barcelona, Taurus, 1993, p. 204. 
principal espacio de desarrollo social de la mujer, donde era la protectora de los valores familiares y la religión católica. ${ }^{12}$

Ellas trabajaron mano a mano con figuras de la alta jerarquía eclesiástica como el arzobispo de México, José Mora y del Río (1904-1928), quien les proporcionó su lema "Restaurarlo todo en Cristo"13 a fin de identificar a las Damas con una nueva estrategia de la jerarquía eclesiástica, conocida como catolicismo social, que inspirada en la encíclica Rerum novarum ${ }^{14}$ proponía una serie de medidas defensivas de los valores cristianos y reivindicaba el papel político de la Iglesia. Así, se establecieron nuevas formas de relación entre la Iglesia y la sociedad a partir de la creación de organizaciones de ayuda mutua, cooperativas, sindicatos obreros católicos y partidos políticos reformistas, que condenaban la injusticia social y destacaban el papel de la fe católica, base de cualquier relación social y laboral.

Además, el arzobispo les impuso una organización interna conformada por tres grupos estructurados jerárquicamente. El primero, estuvo formado por los "directores" o representantes eclesiásticos que acudían a las reuniones, señalaban la forma de trabajo y las estrategias a seguir. Entre los principales asesores de las Damas encontramos al jesuita Alfredo Méndez Medina y al que posteriormente sería arzobispo de México Miguel Darío Miranda, principales impulsores del catolicismo social en las primeras décadas del siglo xx, quienes pretendían frenar el avance de las políticas liberales y revolucionarias.

${ }^{12}$ Este cambio ha sido denominado por la historiografía “un proceso de feminización” de la piedad y las prácticas religiosas, debido a que las mujeres comenzaron a hacerse cargo de actividades devocionales en mayor medida que los hombres. Sin embargo, al igual que Silvia Arrom, considero que esta "feminización fue un desinterés masculino por la piedad y la devoción que una división del trabajo por género. Las mujeres se hicieron cargo de la caridad, la devoción y la filantropía, mientras que la piedad masculina floreció en la creación de organizaciones militantes que actuaron políticamente. Arrom, Volunteering for a Cause..., p. 20-28.

13 "Reglamento General de la Asociación de Damas Católicas Mexicanas", México, julio de 1912, p. 4, Archivo Histórico de la Arquidiócesis de México (Анам), Fondo Arzobispo José Mora y del Río, Sección Secretaría Arzobispal, Serie Asociaciones Piadosas, caja 186, exp. 11.

${ }^{14}$ La encíclica Rerum novarum se publicó en el año 1891, se pronunciaba contra la miseria y la explotación de la clase trabajadora; defendía los principios de caridad, el derecho natural a la propiedad privada, el individualismo, el matrimonio y la familia como base de la sociedad. Para el Sumo Pontífice la humanidad se alejaba cada vez más de los valores cristianos; de este modo, la pobreza, las enfermedades, la criminalidad y las transformaciones sociales que trajo la modernidad fueron percibidas como "la cuestión social". En León XIII, "Carta encíclica Rerum novarum" [en línea], http://w2.vatican.va/content/leo-xiii/es/encyclicals/documents/hf_l-xiii_enc_15051891_rerum-novarum.html 
El segundo grupo estaba formado por la "junta central directiva" ${ }^{15}$ que contaba con tres instancias: una mesa directiva, ${ }^{16}$ un comité general consultor y un comité general de acción social. ${ }^{17}$ Esta junta se componía de mujeres que ocuparon los principales cargos administrativos al interior de la organización. Ellas pertenecían a las clases más conservadoras y mejor acomodadas de la ciudad de México. Por ejemplo, la familia de la presidenta de la organización Elena Lascuráin de Silva, era dueña de una próspera empresa inmobiliaria. ${ }^{18}$

En el último grupo se encontraban las "socias activas" o "celadoras", encargadas de realizar el trabajo social en los barrios y colonias de la ciudad. Para este sector, formar parte de las Damas Católicas implicaba el reconocimiento de una posición de estatus moral en sus comunidades; al mismo tiempo, ingresaban a un sistema de protección y apoyo de mujer a mujer, que ofrecía ayuda y asesoría a mujeres solteras, solas, viudas o abandonadas, porque pertenecer a una asociación católica implicaba formar parte de un sistema que pugnaba por proteger a mujeres, niños, enfermos y menesterosos frente a las desavenencias de la modernidad.

Gracias a la actividad constante de las mujeres líderes y las socias "activas”, las Damas Católicas comenzaron a tener presencia en la ciudad de México. Se dedicaron a establecer vínculos de solidaridad al interior de sus barrios y colonias trabajando directamente en los templos locales, donde impulsaron una diversidad de acciones, tales como la enseñanza del catecismo y del oratorio a niños y obreras. Fundaron círculos de estudio; dieron

${ }^{15}$ La Junta Central Directiva se ocupó de establecer el tipo de actividades que se llevaron a cabo en los distintos centros de acción o secciones, localizados a lo largo de las ocho demarcaciones de la ciudad de México, además contaba con tres instancias, una mesa directiva, un comité general consultor y un comité general de acción social.

${ }^{16}$ La mesa directiva se formó por una presidenta, una o dos vicepresidentas, dos secretarias generales, una tesorera general y una protesorera, todas serían elegidas directamente por el director general, cargo que recayó nuevamente en el jesuita Carlos M. Heredia. La presidenta fue doña Trinidad Sánchez de Tamariz, y sus vicepresidentas, la señora Concepción Vértiz de Quintanilla y la señora Margarita Ordozgoiti de Elguero, la tesorera fue la señora Carlota L. de Algara. "Primer Consejo Directivo", Acción Femenina, México, t. III, n. 9, 1o. de septiembre de 1937, p. 8.

17 El comité general consultor agrupó a todas las celadoras generales, presidentas de las juntas seccionales. Por su parte el comité general de acción-social se componía por las presidentas de las diversas comisiones de acción social quienes se encargaban de las labores propagandísticas. Ambos comités se reunirían los primeros viernes de cada mes para presentar sus informes mensuales y entregar los donativos.

${ }^{18}$ Graziella Altamirano, Pedro Lascurain: un hombre en la encrucijada de la revolución, México, Instituto de Investigaciones Dr. José María Luis Mora, 2004, p. 23-24. 
atención en cárceles, hospitales, hospicios y asilos; crearon un costurero para pobres; fomentaron obras de los tabernáculos; imprimieron y difundieron propaganda contra la pornografía, las malas lecturas, las modas indecorosas y diversiones inconvenientes, entre otras.

Otras investigaciones en torno a las Damas Católicas han destacado el papel de la asociación como parte del movimiento del catolicismo social. La intención de dichas investigaciones es señalar cómo las Damas Católicas formaron parte del conjunto de organizaciones cuyo desempeño fue clave para comprender las estrategias diseñadas por la jerarquía eclesiástica para ganar influencia política. ${ }^{19}$ Sin embargo, poco se ha investigado sobre el impacto que sus acciones tuvieron en el espacio urbano de la ciudad de México, razón por la cual este texto analiza la forma en que la UDCM (19121932) promovió su programa de acción social y político sobre las diversas dimensiones del espacio urbano de la ciudad de México: la manzana, la parroquia, los barrios y las colonias.

Para lograr este objetivo, se examinó, entrecruzó y se ubicó en un plano la información obtenida de fuentes como informes proporcionados por la organización en su principal órgano de difusión, la revista La Dama Católica, descripciones ubicadas en las actas del Consejo General y del Consejo de Vocales Delegadas que se encuentran en el Archivo Histórico de la Unión Femenina Católica de México (AнufCM) ubicado en la Biblioteca Francisco Xavier Clavigero de la Universidad Iberoamericana, así como documentos proporcionados por la policía de investigación de la Secretaría

${ }^{19}$ Hanson, The Day of Ideals...; María Gabriela Aguirre Cristiana, ¿Una historia compartida? Revolución Mexicana y catolicismo social, 1913-1924, México, Instituto Mexicano de Doctrina Social Cristiana/Instituto Tecnológico Autónomo de México/Universidad Autónoma Metropolitana, 2008, p. 221-238; Yolanda Padilla Rangel, Después de la Tempestad. La reorganización católica en Aguascalientes, México, El Colegio de Michoacán/Universidad Autónoma de Aguascalientes, 2001, 403 p.; Kristina A. Boylan, Mexican Catholic Women's Activism, 1929-1940, tesis para obtener el grado de doctor en Filosofía, Londres, Universidad de Oxford, 2000, p. 25-266; Kristina A. Boylan, "Género, fe y nación. El activismo de las católicas mexicanas, 1917-1940”, en Gabriela Cano, Jocelyn Olcott y Mary Kay Vaughan (comps.), Género, poder y política en el México posrevolucionario, México, Fondo de Cultura Económica, 2009, p. 309-346; Juan Pablo Vivaldo Martínez, La Unión de Damas Católicas Mexicanas 1912-1929. Una historia política, tesis para obtener el grado de maestro en Historia, México, Universidad Autónoma Metropolitana, 2011, 157 p.; Patience Shell, “An Honorable Avocation for Ladies: The Work of the Mexico City Unión de Damas Católicas Mexicanas, 1912-1926", Journal of Women's History, v. 4, n. 4, 1999, p. 78-103; Patience Shell, Church and State Education in Revolutionary Mexico City, Tucson, Universidad de Arizona, 2003, 253 p. 
de Gobernación que se localiza en el fondo de la Secretaría de Gobernación, Sección Dirección de Investigaciones Políticas y Sociales (DGIPS) del Archivo General de la Nación. Gracias a esta documentación logré analizar la forma en que la ciudad permitió a la UDCM construir un entramado social propio, mediante el cual actuaron en distintos campos de manera simultánea, múltiple y articulada que les dio soporte.

El presente artículo también destaca el papel de la parroquia como una institución fundamental en la composición y la adaptación de las Damas Católicas en la estructura urbana. Asimismo, se revisa la importancia de las parroquias, que fueron parte esencial de la trama de la ciudad de México y se destaca su función en la militancia católica femenina, ya que fue un espacio clave en su organización interna y en el fomento de sus redes de cohesión social, mediante un trabajo constante y cotidiano que les permitió poner en marcha una red de seguridad capaz de preservar el ejercicio de la práctica religiosa durante los años de mayor persecución.

\section{El comienzo de la vida parroquial (1912-1917)}

Las Damas Católicas se instituyeron en el año de 1912 como parte de las redes seglares que se organizaron en apoyo al PCN que buscaba participar políticamente en el proceso electoral que llevó al poder a Francisco I. Madero. Durante este periodo, la ciudad de México se convirtió en un centro de discusión de corrientes políticas entre diversas organizaciones, que enfrentó a la Iglesia a nuevas posibilidades de participación pública. ${ }^{20}$ Los

${ }^{20}$ La ruptura que representó el cambio del régimen porfiriano al gobierno maderista fue tan profunda que afectó los límites sociales y las líneas que dividían espacialmente a la población. En este sentido, florecieron las sociedades mutualistas, apoyadas directamente por el recién creado Departamento del Trabajo. Su principal intención fue "asegurar la paz industrial", evitando la confrontación directa de los trabajadores con los patrones, protegiendo a niños y mujeres en su lugar de trabajo y desalentando la creación de organizaciones radicales. Se sugiere revisar: María Eugenia Chaoul Pereyra, Entre la esperanza de cambio y la continuidad de la vida. El espacio de las escuelas primarias nacionales en la ciudad de México 1891-1919, México, Instituto de Investigaciones Dr. José María Luis Mora, p. 171; Felipe Arturo Ávila Espinosa, “Organizaciones, influencias y luchas de los trabajadores durante el régimen maderista”, Estudios de Historia Moderna y Contemporánea de México, n. 18, 1998, p. 121-170; John Lear, "Del mutualismo a la resistencia: las organizaciones laborales en la ciudad de México de fin del Porfiriato a la Revolución”, en Carlos Illades y Ariel Rodríguez Kuri (comps.), Ciudad de México: instituciones, actores sociales y conflicto político 1774-1931, México, El Colegio de Michoacán/Universidad Autónoma Metropolitana, 1996, p. 288. 
católicos organizados en torno a la Iglesia participaron activa, pública y políticamente apropiándose de las calles de la ciudad. La militancia católica construyó un discurso social que se expresó en acciones al interior de las parroquias y en las calles de la ciudad. Las Damas Católicas, se fundaron con fines enfocados a la caridad y la acción social, pero sobre todo, hacia la promoción del catolicismo entre la sociedad, aspecto que implicaba el trabajo constante con sacerdotes, templos y parroquias. Así, poco a poco, la organización se convirtió en un brazo que le permitió a la Iglesia actuar sobre el espacio territorial de la ciudad.

Haciendo uso de "las estrechas ligas que sus dirigentes mantenían con párrocos y establecimientos católicos", ${ }^{21}$ pusieron en marcha una serie de lazos de solidaridad fomentados a través de actividades dirigidas en tres direcciones: la recolección de recursos económicos para la "acción social", la publicación de una revista titulada La Mujer Católica Mexicana, dedicada a promocionar "los trabajos personales de las principales damas", ${ }^{22}$ y la realización de actividades devocionales en diversas zonas de la ciudad de México tal y como se explicará a continuación.

En este periodo, la estructura espacial parroquial $^{23}$ de la ciudad de México acababa de pasar por un proceso de reestructuración gracias a que el arzobispo de México, Próspero María Alarcón y Sánchez de Barquera (1891-1908), decidió en el año de $1902^{24}$ ampliar el número de parroquias

${ }^{21}$ O'Dogherty, De urnas y sotanas..., p. 108.

${ }^{22}$ La Mujer Católica Mexicana. Órgano de la Confederación Nacional de Damas Católicas, año IV, n. 20, 1 de julio de 1914.

${ }^{23}$ Por espacio parroquial me refiero a la división territorial eclesiástica que está bajo el mando de un párroco o rector, que regula los servicios correspondientes a los sacramentos, el bautizo, el matrimonio, los enfermos y los entierros. Es decir, la parroquia desde el periodo colonial fue el espacio que dio estructura a la vida social y orden al espacio urbano de la ciudad de México.

${ }^{24}$ Ernest Sánchez Santiró señala que, desde la conquista, la ciudad de México quedó constituida en dos administraciones "la república de indios" y la "república de españoles", a dicha división se incorporó también la estructura eclesiástica. Entre 1534 y 1624, se utilizaron los términos de parroquia de españoles y doctrina de indios para referirse intencionalmente a las demarcaciones territoriales, que ordenaban a las poblaciones para la administración de los sacramentos. Hacia 1624, señala el autor, las "doctrinas indias de la Nueva España” pasaron a convertirse en parroquias regulares. Sin embargo, la división étnica se mantuvo hasta los años sesenta del siglo XVIII, fecha en que se reformó el orden eclesial capitalino, basado en la supuesta territorialidad, dada la búsqueda de la división étnica de los feligreses. La intención fue dar inicio a un proceso de secularización parroquial, para imponer el reformismo borbónico a la estructura eclesial e incorporar a los indígenas a la sociedad novohispana mediante la castellanización. A partir de 1772, la estructura parroquial novo- 
de 13 a $17^{25}$ e incorporar cinco vicarías, ${ }^{26}$ tal y como se puede observar a través de las líneas amarillas del plano 1 . El objetivo fue adec crecimiento urbano y tener mayor control sobre las actividades pastorales ${ }^{27}$ uar el espacio al para centralizar y normalizar las relaciones de poder entre el clero y sus feligreses.

Esta transformación estableció una mayor responsabilidad al párroco para interactuar con sus congregados y promover el catolicismo social. Diez años después, con ayuda del arzobispo José Mora y del Río (1854-1928), las Damas Católicas trabajaron dentro de los templos para extender las actividades parroquiales hacia el espacio urbano. En el plano 1 se puede observar el espacio de trabajo de las Damas Católicas en iglesias ubicadas en las Parroquias Santa Vera Cruz, San Sebastián, Sagrario, Santa Cruz y Soledad, San Miguel, San Pablo, Salto del Agua y San Cosme y en las vicarías Campo Florido, San Francisco Tepito y Sagrado Corazón de Jesús. En ellas se establecieron células denominadas "juntas seccionales”. Cada célula se integró con tres socias "celadoras" generales, quienes fungieron con los cargos de presidenta, secretaria y tesorera y se reunían una vez por semana. Se les denominó “celadoras”, porque tenían las obligaciones de vigilar, recolectar donativos y repartir hojas de propaganda en las manzanas de sus colonias y barrios; ellas eran las "abejas obreras" y conformaron las bases sociales de la organización. Una vez al mes, se llevaba a cabo una junta general, en donde se reunían todas las celadoras del distrito a rendir

hispana, basada en el principio de la separación étnica que dividía a la "república de españoles" de la "república de indios" desapareció para dar paso a un nuevo orden ilustrado, cimentado en la evolución demográfica, social y económica de la ciudad de México y en su lugar se erigieron 13 parroquias para atender las necesidades espirituales de los habitantes de la capital. Ernest Sánchez Santiró, "El nuevo orden parroquial de la ciudad de México: población, étnica y territorio (1768-1777)”, Estudios de Historia Novohispana, n. 30, 2004, p. 63-92; Lourdes Márquez Morfín, La desigualdad ante la muerte en la ciudad de México. El tifo y el cólera (1813-1833), México, Siglo XXI, 1994, p. 84-85; Francisco Martínez Mesa, De profanos a devotos: la enseñanza elemental católica en la ciudad de México, 1891-1910, tesis de licenciatura en Historia, México, Instituto de Investigaciones Dr. José María Luis Mora, 2015, p. 40.

${ }^{25}$ La ciudad quedó dividida en las parroquias: El Sagrario, Santa Catarina, Santa Vera Cruz, San Miguel, Santa Cruz y Soledad, San Pablo, Santa Ana, San Sebastián, San José, Salto del Agua, Santo Tomás, Santa María la Redonda, Santa Cruz Acatlán, San Cosme, Corazón Inmaculado de María, Concepción Tequipechuca y San Antonio Tomatlán.

${ }^{26}$ San Antonio de las Huertas, De la Roma o Sagrado Corazón de Jesús, Campo Florido, San Miguel Nonoalco, San Francisco Tepito.

${ }^{27}$ Martínez Mesa, De profanos a devotos: la enseñanza elemental católica..., p. 42-43. 
cuentas a las socias líderes, lo que les permitió obtener un diagnóstico preciso de las actividades cotidianas. ${ }^{28}$

Estas "juntas seccionales" se dedicaron a organizar escuelas para niños pobres, obreros y obreras de la ciudad que se ubicaron dentro de los templos; sobre todo, se fundaron escuelas católicas donde se enseñaba la doctrina religiosa, se daban clases de catecismo, se preparaba para la primera comunión y además se enseñaba a leer y escribir. Este tipo de actividades eran complementarias a las labores desarrolladas fuera de los templos; por ejemplo, durante la dictadura huertista se fundó un asilo y una escuela gratuita "para niñas pobres" atendida por monjas salesianas, ubicada en la calle de Jesús María 5 (número 16 en el plano 1). Parte de sus labores fueron consolidar y articular la centralización de la acción social católica de los círculos obreros que se fundaron en la última década del Porfiriato, pero que se encontraban atomizados y no habían podido unificar sus intereses, actividades, ni sentido social. Las Damas mantuvieron sus actividades en al menos, tres templos: la iglesia de Santa María la Ribera, la iglesia de Jesús o la iglesia de Nuestra Señora de Loreto.

Esta organización impidió el contacto horizontal entre "juntas seccionales” y demarcaciones, más bien, emuló el modelo de organización de la milicia ciudadana instituida por el ayuntamiento en marzo de 1912, que pretendía designar en cada una de las manzanas de las ocho demarcaciones de la ciudad "a un individuo de honorabilidad reconocida a efecto de que éste elija bajo su responsabilidad el contingente de guardias de esa manzana”. ${ }^{29}$ Tanto para las Damas, como para la milicia ciudadana, las manzanas funcionaron como la unidad básica de control social, de vigilancia del espacio público, de visibilización, de participación y evaluación de sus actividades.

A partir de la derrota del ejército huertista por las fuerzas constitucionalistas en junio de 1914 las condiciones de la ciudad de México y de las Damas Católicas cambiarían de manera radical. Por un lado, la ciudad quedó secuestrada por los intereses de una u otra facción revolucionaria, que

28 "Primeros trabajos de organización personal", Acción Femenina, México, t. III, n. 9, 1o. de septiembre de 1937, p. 8.

${ }^{29}$ El proceso de organización de la milicia urbana estuvo a cargo de Alberto Braniff, quien era miembro de una de las familias más prominentes del Porfiriato, gracias a sus redes de parentesco y de solidaridad entre amistades y familiares, lograron levantar diversos negocios dentro de los que destacan la compra de grandes terrenos para fraccionarlos y construir casas y colonias habitacionales. María del Carmen Collado Herrera, La burguesía mexicana: el emporio Braniff y su participación política, 1865-1920, México, Siglo XXI, 1987. 
buscó imponerse en la escena política capitalina mutilando el aparato administrativo y las instituciones públicas. ${ }^{30}$ Las Damas sufrieron en carne propia los efectos de esta crisis. La guerra, la violencia, la inflación y el desabasto afectaron directamente su estructura organizativa. El apoyo que la jerarquía eclesiástica y los miembros del PCN dieron a la presidencia de Victoriano Huerta los convirtió en los principales enemigos de los revolucionarios carrancistas, villistas y zapatistas, lo que inició una campaña de persecución a sacerdotes y militantes católicos. Muchos pasaron a la clandestinidad, los más afortunados abandonaron el país. Esta situación puso a las Damas Católicas en una posición de vulnerabilidad; de acuerdo con sus propios registros el número de socias se redujo de 6120 a ocho ${ }^{31}$ y las actividades que se realizaban en al menos 22 templos prácticamente desaparecieron.

Al mismo tiempo, la ciudad vivió una fuerte crisis alimentaria, los precios del maíz, el frijol, el arroz, el trigo y el azúcar aumentaron entre $200 \%$ y $900 \%,{ }^{32}$ lo que provocó hambruna, desempleo y violencia. Ante esta crisis, las mujeres que se mantuvieron dentro de la organización trabajaron desde espacios privados, es decir, sus casas y buscaron el apoyo de otros grupos políticos como el Ayuntamiento de la ciudad y los comerciantes a fin de organizar diversas medidas que proveyeran a las familias más necesitadas de semillas y otros alimentos. ${ }^{33}$ Pese a la crisis, las Damas lograron sostener un ropero y un comedor para personas de bajos recursos ubicados en las colonias Roma y San Rafael.

Entre 1914 y 1916, sus actividades adquirieron tintes de ayuda humanitaria. Ante la falta de alimentos, la fuerte hambruna y las enfermedades que azotaron las calles de la ciudad, las Damas respondieron al estado de emergencia como un "ejército". Esto les permitió salvaguardar el mayor número de vidas posible. Así, sus acciones fluyeron de la casa de la presidenta de la asociación Elena Lascuráin a centros específicos: como su comedor, cuarteles de los principales líderes revolucionarios como Francisco Villa, Álvaro Obregón y Venustiano Carranza, y templos clave para la alta

${ }^{30}$ Chaoul, Entre la esperanza de cambio y la continuidad de la vida..., p. 184.

${ }^{31}$ Chaoul, Entre la esperanza de cambio y la continuidad de la vida..., p. 184.

${ }^{32}$ Ariel Rodríguez Kuri, “Desabasto, hambre y respuesta política, 1915”, en Carlos Illades y Ariel Rodríguez Kuri (comps.), Instituciones y ciudad. Ocho estudios históricos sobre la ciudad de México, México, ¡UníoS!, 2000, p. 137-138.

33 "Acta de la Junta del mes de 12 de noviembre de 1914", en Universidad Iberoamericana (UIA), Biblioteca Francisco Xavier Clavigero (BFXC), Archivo Unión Femenina Católica de México (Анufcm), Libro de Actas del Consejo General, 1913-1923, p. 13. 
jerarquía eclesiástica como la iglesia de La Profesa. (Esto se observa en las flechas de color morado en el plano 1.)

Por otro lado, entre 1912 y 1917, la Junta Central Directiva estableció tres centros de trabajo: la iglesia de La Profesa, en las oficinas de los Caballeros de Colón y en el edificio del Seminario Conciliar. ${ }^{34}$ En estos espacios se tomaron las decisiones más importantes de la organización, se definió su estructura interna, su funcionamiento y su identidad. Cabe señalar que dos de los tres principales centros de decisión se encontraban circunscritos espacialmente a la parroquia de El Sagrario, donde se ubica la Catedral de México.

Su cercanía con la parroquia El Sagrario simbolizaba un vínculo con el poder eclesiástico. Desde ahí se extendería el área de influencia de las Damas Católicas hacia el oriente, en las parroquias de Santa Cruz, San Sebastián y San Francisco Tepito, donde se ubicaban las colonias más marginales de la ciudad actuaron con los programas de atención a la educación obrera. Hacia el poniente, en la parroquia de la Santa Vera Cruz que atendió los barrios que sufrieron la pauperización urbana a raíz del abandono de las clases altas del centro de la ciudad, se instaló un asilo, se fundó una escuela para obreros y también se sostuvo el Colegio Josefino, contiguo al templo de Santa Brígida. Al sur y sur poniente la acción se llevó a cabo hacia las vicarías de Campo Florido y del Sagrado Corazón de Jesús en particular en el barrio de La Romita donde se instaló también una escuela nocturna. (Véase el plano 1.)

Las Damas Católicas se adaptaron a las circunstancias y adversidades que se le presentaron, mostrando su enorme capacidad de dialogar con el contexto y responder a las dificultades. Esta habilidad de adaptación fue el elemento que le permitió permanecer activa y visible en la vida pública, lo que posibilitó su organización logística para sobrevivir en los periodos de crisis y restablecerse a partir de 1917, momento en que la organización comenzó a recobrar su número de socias, lo cual se verá en el siguiente apartado.

Más allá de los templos. La profesionalización y las actividades en el espacio urbano (1917-1926)

Con la elaboración de una nueva constitución que estableció artículos como el tercero, donde se instituyó la educación laica y se prohibió la participación

${ }^{34}$ Información recuperada de las Actas de las Juntas del Consejo General de la organización, UIA, BFXC, AHUfCM, Libro de Actas del Consejo General, 1913-1923. 
de las corporaciones religiosas, o el artículo 130 que imposibilitó la participación política y pública de los ministros de culto al impedir actos públicos de propaganda religiosa o política, la jerarquía eclesial cerró filas y modificó las formas de participación pública de sus organizaciones católicas para convertirlas en militantes de la causa católica con un grado mayor de beligerancia, lo que afectó directamente la vida asociativa y las prácticas cotidianas de las Damas Católicas. Se convirtieron en profesionistas y gestoras de la defensa de los valores católicos a través del trabajo directo, constante y cotidiano con mujeres obreras, trabajadoras empleadas, niños pobres o huérfanos, enfermos y prisioneros. La intención fue crear una telaraña social capaz de sostener al catolicismo, al tiempo que generó lazos de cohesión entre la sociedad de la ciudad de México. Con la intención de extender el papel de la mujer católica como eje de la vida doméstica a campos públicos, donde era indispensable su labor.

Las Damas crearon un programa de acción social que apelaba a la conservación de un modelo de mujer tradicional, hogareña y católica. Generaron un modelo de atención en diversos establecimientos como centros educativos y atención a niños, obreras, sindicatos de trabajadoras católicas y casas de regeneración para prostitutas que salían del Hospital Morelos. De esta forma, extendieron e institucionalizaron sus actividades fuera del espacio parroquial y con ello profesionalizaron y adecuaron su trabajo a las nuevas circunstancias.

De manera paralela, los gobiernos de Adolfo de la Huerta, Álvaro Obregón y Plutarco Elías Calles pretendían convertir el espacio urbano en un espacio social, abierto para el esparcimiento, disfrute, convivencia y uso de todos los sectores de la ciudad. Pese a la crisis económica nacional los primeros gobiernos posrevolucionarios impulsaron una serie de reformas urbanas, caracterizadas por la edificación de monumentos, embellecimiento y remodelación de edificios públicos; por ejemplo, se limpió y amplió la fachada del Palacio Nacional y se modificó la imagen de la plaza mayor. ${ }^{35}$ Por su parte, las Damas Católicas buscaron formas de participación pública para hacerse visibles en las calles, colonias y barrios de la ciudad de México.

Así, la llegada del Grupo Sonora al poder y su interés por impulsar un Estado laico abonó el terreno para que las Damas Católicas transformaran

${ }^{35}$ María del Carmen Collado Herrera, "Los sonorenses en la capital”, en María del Carmen Collado Herrera (coord.), Miradas recurrentes I. La ciudad de México en los siglos XIX y XX, México, Instituto de Investigaciones Dr. José María Luis Mora, 2004, p. 102. 
su organización interna. Dejaron de trabajar manzana por manzana para actuar en torno a 15 "secciones" que operarían de manera simultánea por la ciudad. Dentro de estas secciones destacan: la Sección de Extensión que se dedicó a generar actividades propagandísticas; las secciones Catequísticas, Entronizaciones ${ }^{36}$ y Estudios Religiosos, se destinaron a promover la fe y la doctrina religiosa; la Sección de Seminario se dirigió a apoyar económicamente a estudiantes del Seminario Conciliar; la de prensa se encargó de publicar los diversos órganos propagandísticos de la Unión como la revista La Dama Católica (1920-1926); la de Escuelas fomentó la libertad de enseñanza religiosa en los colegios privados; la de Trabajo promovió la doctrina católica entre obreras de la capital. ${ }^{37}$ Por último, se fundó el "Ejército de Defensa de la Mujer”, que se encargó de ofrecer apoyo espiritual a mujeres internadas en el Hospital Morelos. ${ }^{38}$

Estas secciones además de definir los campos de acción de las Damas convirtieron su vida asociativa en una maquinaria con engranajes precisos, con objetivos y tiempos claros, al tiempo que propició su proceso de profesionalización. El diseño de las políticas de cada sección muestra un cambio en el método de trabajo, es decir las Damas comenzaron a actuar por metas, bocetaron su camino a seguir, organizaron sus actividades en torno a la recaudación económica necesaria para cubrir sus metas y objetivos.

Entre 1920 y 1926 establecieron su primera sede en un edificio que estaba fuera de los templos, más no fuera del espacio de dominio de la parroquia más importante, el Sagrario. El edificio social, como lo llamaron, se convirtió en su centro de operaciones, donde se dirigían las actividades que se desarrollaban en todo el distrito federal. Al sur en la municipalidad de San Ángel, las damas abrieron colegios en un lugar que describían como "eminentemente fabril, donde hay mucho huérfano y madres solteras". ${ }^{39}$ Hacia el norte, en Azcapotzalco, que poco a poco se convertía en una zona

${ }^{36}$ La entronización era un elemento de la devoción al Sagrado Corazón que representaba un nuevo vínculo entre los creyentes y la fe, ya que simbolizaba "el inicio del final de una era regida por el pecado y la impiedad para dar lucha al reinado social, entendiendo que la violencia era sólo un episodio para purificar la patria”, en Moreno Chávez, Devociones políticas. Cultura católica y politización..., p. 189.

${ }^{37}$ Información obtenida de los UiA, BғXC, AHufCm, Libros de Actas del Consejo General.

${ }^{38}$ Katherine Elaine Bliss, "Theater of Operations: Reform, Politics, and the Battle for Prostitutes' Redemption at Revolutionary Mexico City's Syphilis Hospital”, en Stephanie Mitchell and Patience Schell (eds.), The Women's Revolution in Mexico, 1910-1953, Lanham, Rowman and Littlefield, 2007, 243 p.

39 “Lo que hacen las damas”, La Dama Católica, t. II, n. 33, 1 de junio de 1923, p. 39. 
industrial importante, establecieron una escuela. Al nororiente, en las colonias Peralvillo, Vallejo, Valle Gómez y la Bolsa, zonas que se caracterizaban, de acuerdo con las Damas, por la pobreza y la inmundicia de todos los días, debido a la falta de servicios públicos básicos, como agua, luz, drenaje y pavimento. ${ }^{40}$ Su labor se dirigió a los sectores más desfavorecidos, hacia el norponiente de la capital, trabajaron en colonias de medianos recursos como Santa María la Ribera, donde establecieron espacios de resguardo para mujeres que anteriormente se dedicaban a la prostitución; también actuaron en la colonia Popotla, que era una zona de muy escasos recursos (véase el plano 2).

Gran parte de las mujeres que trabajaban en estas comunidades habitaban en esas zonas y desarrollaban sus actividades con el apoyo del párroco más cercano. Considero que eran las antiguas socias celadoras, es decir, pese a la crisis que vivieron durante la Revolución Mexicana, las Damas mantuvieron lazos con sus antiguas socias. Mientras las señoras de la oligarquía conformaron las mesas directivas, se dedicaron a dirigir y organizar las secciones, fueron las antiguas socias celadoras quienes se encargaron de ejecutar las actividades en sus barrios y colonias.

Parte importante de la acción de las Damas Católicas implicó un enfrentamiento directo con las políticas estatales impuestas en la Constitución de 1917. Así, pese a la serie de restricciones señaladas en el artículo tercero, que imponía la educación laica, la sección de escuelas se dedicó a fundar varios colegios católicos. Se fundó el Colegio Italiano (Calle Jesús María 5), el Colegio de San Felipe de Jesús (Academia 13), ${ }^{41}$ la Escuela Granja de la Colonia Vallejo (Esparta 5006), la Escuela Sor Juana Inés de la Cruz (para los hijos de las mujeres que trabajan en la fábrica de camisas La Britania, ubicada en la calle Degollado 223), el Colegio Gratuito de María Auxiliadora para Niñas, el Colegio Gratuito de San Jacinto y el Asilo para Niños Huérfanos y abandonados de San Jacinto en San Ángel (Plaza San Jacinto 13), la Escuela Católica Reforma (en Calzada Imparcial, en Azcapotzalco), el Centro Libre de Educación Nacional (o Escuela Libre Preparatoria) ${ }^{42}$ el Colegio del Sagrado Corazón de Jesús (México 4a. San Joaquín 91, Peralvi-

${ }^{40}$ Ernesto Aréchiga Córdoba, Tepito: del antiguo barrio de indios al arrabal, 1868-1929. Una historia de una urbanización inacabada, México, ¡UníoS!, 2003, 365 p.

${ }^{41}$ Se encontró primero en la calle de Santa Inés, n. 3, "Lo que hacen las damas", La Dama Católica, t. IV, n. 51, 1 de diciembre de 1924, p. 16.

${ }^{42}$ No se encontró la dirección. 
1lo), Escuela Diurna (Casa del Papelero), Colegio Católico (Tlalnepantla) ${ }^{43}$ (véase el plano 2 ).

Como se aprecia en el plano 2, la acción de las Damas Católicas se desprendía de los centros de decisión y se dirigía al resto de sus centros de acción. Lo interesante es que abarcaron sobre todo barrios marginales y obreros, lo que habla de la capacidad de las Damas de introducir su acción en aquellos espacios donde existía un vacío de autoridad; en lugares donde el gobierno no lograba introducir los servicios públicos. Por ejemplo, la zona de Peralvillo y Vallejo contaba con una población de 11000 habitantes $^{44}$ en su mayoría obreros y grupos marginales; la zona no tenía un sistema de tuberías, tal y como lo demuestran artículos publicados en la prensa de la época donde se hacía hincapié en que el Ayuntamiento de la ciudad de México tenía poco interés por establecer el sistema de desagüe. ${ }^{45}$ Asimismo, existían pocas escuelas en el barrio, inclusive, en 1919 varios vecinos solicitaron a la Dirección General de Educación Pública que la escuela elemental volviera a ser mixta pues era el único centro educativo con el que contaban. ${ }^{46}$ Por su parte, la sección de escuelas de las Damas Católicas demostró una gran capacidad para detectar a aquellos grupos sociales con necesidades educativas: niños y obreros que vivían en estos barrios de la ciudad. Así, los planteles tuvieron más de una función, es decir, por las mañanas se dedicaban a la educación de la infancia, por las noches enseñaban a obreras y los fines de semana se convertían en pequeños centros comunitarios donde se promovía la sociabilidad, realizaban misas y daban clases de religión y catecismo.

Por otro lado, la Sección de Trabajo pretendía "defender los intereses morales y materiales de la obrera". ${ }^{47}$ Para lograr estos fines fundó un sindicato católico y un centro de educación para mujeres obreras y cursos nocturnos de enseñanza a trabajadores. Las Damas consideraban necesario mantener los problemas obrero-patronales dentro de lo privado. Las socias trabajaron tanto dentro de las instalaciones como en las calles y esperaban en las banquetas el fin de la jornada laboral para promocionar los objetivos

\footnotetext{
${ }^{43}$ Información recuperada de las actividades reportadas en la revista La Dama Católica y en las actas del Consejo General de las Damas Católicas.

44 "Hablando de Terrenos, aquí los hay en distintos rumbos", El Universal, ciudad de México, 25 de junio de 1922, tercera sección, p. 4.

45 "Buena parte de la capital no tiene obras de drenaje”, Excélsior, ciudad de México, 28 de julio de 1921, p. 1.

46 "Faltan escuelas en el barrio de Peralvillo", El Universal, ciudad de México, 21 de julio de 1919, p. 2.

47 “Sección del Trabajo", Acción Femenina, t. III, n. 9, 1 de septiembre de 1937, p. 20.
} 
y ventajas de su sindicato. ${ }^{48}$ Esta estrategia les permitió tener una presencia en diversas fábricas de la ciudad distribuidas por distintas zonas. Lograron inscribir a su sindicato a obreras de las fábricas Camisas La Britania, Chocolates Larín, Velas La Moderna, La Pasamanería Francesa y La Esperanza.

Además, instauraron un sindicato de enfermeras dentro del Hospital General, donde acudían a atender las necesidades espirituales de los enfermos. A partir de 1921, decidieron proteger a las enfermeras, organizaban fiestas para ellas, rifaban premios, ofrecían pláticas en torno del trabajo, la moralidad y la religión. Así, fundaron una capilla dentro del hospital, donde promovían los bautizos de los recién nacidos y les repartían ropa que ellas mismas cosían. ${ }^{49}$

Su rol de género les permitió comprender los problemas cotidianos de las obreras por ejemplo, mantener una casa, abastecer la despensa, alimentar a hijos y esposos, y al mismo tiempo trabajar una jornada laboral de 12 o más horas. Para ello, definieron una estrategia que combinaba prácticas conservadoras y tradicionales con demandas obreras modernas. Utilizaron sus lazos de parentesco y amistad con los directivos de algunas fábricas, como la ya mencionada Britania, para instalar guarderías; de esta forma se trasladó parte de la vida doméstica de las trabajadoras al espacio laboral.

Al no existir una ley federal del trabajo que prohibiera las agrupaciones confesionales de trabajadores, entre 1920 y 1924, las organizaciones obreras católicas participaron pública y libremente. Fue una forma de incorporar en sus filas a mujeres que se beneficiaban de distintas formas. Creaban lazos de sociabilidad, aprendían nuevas habilidades y técnicas laborales, pertenecían a una comunidad que las ayudaba con guarderías, escuelas para sus hijos, juguetes y alimentos, la intención última era cohesionar a la población obrera en torno de la Unión de Damas Católicas, sobre todo, alrededor de la devoción y la fe cristiana.

Por otro lado, las secciones Catequística, de Entronizaciones, Moralidad y Cinematografía, les permitieron utilizar su devoción y su práctica religiosa como guía para la vida, para el bien vivir. Las secciones Catequística y de Entronizaciones se dedicaron exclusivamente al proselitismo, convencimiento y adoctrinamiento religioso. La primera se encargó de difundir el

48 “Informes y sugestiones”, La Dama Católica, t. I, n. 12, 31 de agosto de 1921, p. 15.

49 "Informes y sugestiones. Vea usted lo que hacemos. Vea usted en qué puede ayudarnos. Vea usted lo que puede hacer en su ambiente o en su ciudad. ¡A trabajar con entusiasmo y amor!", La Dama Católica, t. II, n. 12, 30 de septiembre de 1921, p. 19; "Lo que hacen las damas", La Dama Católica, t. III, n. 31, 1 de abril de 1923, p. 18. 
catecismo en escuelas y casas particulares, así como promover y organizar los matrimonios eclesiásticos, bautismos y primeras comuniones. La segunda buscó imponer el reinado de Jesucristo de manera simbólica en el mayor número de hogares, escuelas, fábricas y empresas. Por medio de estos actos devocionales se dio un sentido político al culto privado, pues se identificaba públicamente el espacio doméstico y laboral con la causa de la Iglesia y al mismo tiempo, las Damas se distinguían y posicionaban ante la sociedad como las proveedoras de la fe y la moral católica.

Estas secciones conformaban los "ejércitos-hormiga" de las Damas Católicas pues, llevaban la religión de puerta en puerta y se reafirmaba el papel de la Iglesia como un actor clave en la vida social. Las entronizaciones y la enseñanza del catecismo les permitían incursionar en el espacio doméstico para transmitir la moral y la fe católica en los hogares de la ciudad y así extender sus bases sociales. Además, cada sección y centro local organizaba festivales, kermeses de caridad, fiestas y recepciones en diversos puntos de la ciudad de México, por ejemplo, la Junta Moralizadora de la Colonia Cuauhtémoc rentaba el jardín del restaurante Chapultepec y colocaban puestos donde expedían confeti, sándwiches y ponches; se disfrazaban con "trajes de fantasía" para atender a su enorme concurrencia. La Junta de Damas de Popotla, de la misma forma, rentaba el salón del cine Iris para desarrollar sus festivales de caridad, donde llevaban a escena algunas comedias que interpretaban las mismas "distinguidas señoritas y caballeros de la localidad". ${ }^{50}$

Las secciones y centros ocupaban la ciudad de México para promover actividades de moralización con niños, jóvenes y padres de familia, que incluían desde las formas de vestir a fin de evitar que las mujeres y niñas se interesaran en las tendencias de moda, como el cabello corto estilo Bob y el desuso del corsé que, para las Damas Católicas, eran inspiradas "por judíos y francomasones como medios de corrupción y perversión", ${ }^{51}$ hasta el tipo de música que debían escuchar a fin de prohibir bailes y danzas, como el fox-trot, que para ellas no tenían "ritmo, ni paso, ni elegancia [...] no son más que movimientos inmorales". ${ }^{52}$ De esta forma, las Damas de Popotla o de la colonia Cuauhtémoc se desplazaban de sus barrios hacia otras zonas

50 "Kermesse de caridad", Excélsior. Notas sociales y personales, ciudad de México, 29 de noviembre de 1920, p. 3.

51 "Los bailes modernos, las modas imperantes y la trata de blancas. Una campaña de las Damas Católicas”, El Universal, 10 de noviembre de 1922, p. 8.

52 "Los bailes modernos...", p. 1. 
de la ciudad a fin de promover su devoción y los valores sociales tradicionales. A pesar de recorrer grandes distancias, su constancia y tenacidad nos habla de lo importante que era promover su visión moral católica y al mismo tiempo, generar estrategias que les permitieran mantener sus lazos comunitarios, tener presencia pública para mantener su red de apoyo.

Entre la guerra y la clandestinidad

El programa de las Damas, junto con los de otras organizaciones católicas, comenzó a radicalizarse a partir de 1923, cuando las tensiones entre la Iglesia y el Estado se agravaron producto de la expulsión del país del representante del Vaticano en México, monseñor Ernesto Filippi ${ }^{53}$ y de la publicación de un conjunto de leyes reglamentarias a la Constitución de 1927, en particular, la ley reglamentaria al artículo tercero de la educación y el 123 del trabajo y previsión social.

Como parte del programa de defensa de la Iglesia frente a estas nuevas amenazas, en marzo de 1925, las Damas se unieron a la Liga Nacional de Defensa de la Libertad Religiosa (LNDLR), organismo que se encargaría de coordinar, impulsar y preparar a la militancia católica para actuar contra el gobierno federal y la aplicación de las reglamentaciones a los artículos de la Constitución que mermaban los derechos del clero.

Para estas fechas, las Damas se habían convertido en una organización consolidada a nivel local y nacional. Contaban con una fuerte red de solidaridad al interior de la ciudad de México y ayudaron a la Liga para organizarse territorialmente. Las Damas acudieron a su primera organización territorial por manzanas y por demarcaciones, que les había funcionado muy bien durante la Revolución Mexicana. Conforme a las 10 demarcaciones de la ciudad, se nombraron delegados regionales, jefes locales y agentes de cuadrante, que en su mayoría eran mujeres, probablemente socias de las

${ }^{53}$ Inmediatamente después de que colocara la primera piedra del monumento a Cristo Rey en la cima del cerro del Cubilete, acción que implicaba violar la cláusula constitucional, que no permitía el culto fuera de las iglesias. El artículo 130 constitucional prohibía la participación política de las autoridades religiosas, impedía a los ministros de los cultos participar en actos públicos, realizar actividades de propaganda, hacer crítica a las leyes fundamentales del país. Asimismo, les prohibía el voto y el derecho de asociación; en Constitución Política de los Estados Unidos Mexicanos que reforma la de 5 de febrero de 1857, Querétaro, 1917, p. 84. 
Damas Católicas. Al mismo tiempo, se encargaron de recolectar dinero para los gastos de la Liga y para todos los sacerdotes que tuvieron que abandonar el culto; asimismo, realizaron labores de propaganda. ${ }^{54}$ La experiencia previa de las Damas como gestoras de acción social, aunada a sus fuertes vínculos de sociabilidad, les otorgó una estructura comunitaria que permitió recaudar fondos eficientemente.

Cuando inició la guerra Cristera en agosto de 1926, todas las actividades litúrgicas ejercidas por la Iglesia y el clero pasaron a la clandestinidad. Las actividades de las Damas Católicas también tomaron una nueva dimensión. Los templos y la mayoría de sus centros ubicados en la ciudad desparecieron. Sin embargo, sus actividades se enfocaron hacia la defensa de la fe en el espacio público. Por ejemplo, durante septiembre y octubre de 1926 y a lo largo de $1927^{55}$ y $1928,{ }^{56}$ la LDLR y las Damas Católicas, promovieron el festejo de la fiesta de Cristo Rey. En la ciudad de México estos festejos incluían una peregrinación hacia la Basílica de Guadalupe. ${ }^{57}$ Cabe señalar que las peregrinaciones contaron, de acuerdo con Butler, con alrededor de 200000 participantes; es decir, una quinta parte de la población de la ciudad de México tomó las calles de la ciudad para realizar de manera política, actos litúrgicos. De acuerdo con Butler, las peregrinaciones se convirtieron en rituales de resistencia civil frente al Estado y también permitieron a la militancia católica, en particular las Damas Católicas como organizadoras y activistas lograron realizar actos "cuasisacramentales" similares a los de los párrocos, pues pudieron dar sermones, oficiar comuniones y consagraciones. ${ }^{58}$

Desde mi punto de vista, las actividades de Damas Católicas entre 1920 y 1924 - como las entronizaciones, los catecismos, las kermeses, entre otras- les permitieron forjar redes de apoyo y solidaridad, lo que les ayudó a convertir a la ciudad de México en una zona de protección durante el

54 "Informe", AGN, Fondo Gobernación, Sección DGIPS, caja 0228, exp. 33, clasificación original 313.1-175 [t. 1], ciudad de México, 28 de julio de 1926, f. 61.

${ }^{55}$ Sesión del Consejo de General del 28 de septiembre de 1927, UIA, BFXC, АнUfCM, Libro de Actas del Consejo General, 1926-1928, acta n. 163, p. 106-109.

${ }^{56}$ Sesión del Consejo de General del 18 de octubre de 1928, UiA, BFXC, AнufCM, Libro de Actas del Consejo General, 1926-1928, acta n. 187, p. 153-156.

${ }^{57}$ Sesiones del Consejo de General de los días 28 de octubre y 4 de noviembre de 1926 , UIA, BFXC, AHUFCM, Libro de Actas del Consejo General, 1926-1928, actas n. 132-133, p. 39-45.

${ }^{58}$ Butler señala también que el culto a Cristo Rey fue especialmente fuerte en la ciudad de México; y, al término de la guerra, la Iglesia buscó frenar el culto a Cristo Rey fomentando en su lugar el culto a la virgen de Guadalupe como parte de las medidas tomadas para debilitar la autonomía de la militancia católica. Butler, "Sotanas rojinegras...", p. 155. 
conflicto armado. Gracias a estos lazos pudieron recibir refugiados, esconderlos y protegerlos. Las Damas adquirieron la función de cuidar y proteger a los clérigos encarcelados, les llevaban comida, ropa y dinero, incluso en los casos en que tuvieran que abandonar el país.

Tanto las circunstancias generadas por la guerra como el rompimiento entre la alta jerarquía eclesiástica y el grupo de sacerdotes vinculados a la guerra Cristera les otorgaron mayor autonomía para actuar por la ciudad. Así, las Damas pudieron mantener prácticas devocionales como el rezo del rosario y la fiesta del Sagrado Corazón de Jesús e inclusive, acudían a la iglesia de La Profesa a disponer lo necesario para la misa, pese a la clausura de los templos impuesta por el gobierno. ${ }^{59}$

A diferencia del periodo revolucionario donde las Damas perdieron a sus simpatizantes ante la crisis económica y humanitaria provocada por el impacto de la guerra en la capital del país, durante la guerra Cristera no se menciona una pérdida dramática del número de socias, únicamente se aluden aquellas socias que debían abandonar el país ante la persecución religiosa; sin embargo, este abandono no significó la pérdida del vínculo ni de la cohesión social. Al contrario, se llegó a fundar un centro de Damas Católicas en Los Ángeles, California, mismo que se encargó de rescatar y proteger a los sacerdotes que llegaban a esa ciudad.

El retorno a la parroquia y la pérdida de identidad

Una vez que se firmaron los "Arreglos" en el año de 1929 y se dio por terminada la guerra Cristera, la alta jerarquía eclesiástica impuso una nueva organización bajo el esquema de la Acción Católica, propuesto por Pío XI, como una estrategia que pretendía controlar y vigilar los diversos movimientos católicos por todo el mundo.

La Acción Católica Mexicana (ACM) se definió como "la cooperación organizada y multiforme de los católicos seglares mexicanos en el apostolado de la jerarquía eclesiástica bajo directa dependencia de la misma autoridad, con el fin de cristianizar a la sociedad". ${ }^{60}$ Con la pretensión de

59 “Acta 27. 14 de junio de 1928”, uiA, BfXc, Ahufcm, Libro de Actas del Consejo de Vocales Delegadas, 1925-1928, sesión del Consejo de Vocales Delegadas.

60 "Estatutos Generales de la Acción Católica Mexicana", UiA, BFXC, Archivo de la Acción Católica Mexicana (AACM), Sección Junta Central, Estatutos y Reglamentos, 1927-1938, 1929, f. 2 . 
formar, actuar, difundir y defender los principios cristianos en la vida individual, familiar y social, reordenó a las organizaciones católicas seglares.

La Liga de Defensa de la Libertad Religiosa y la Asociación Católica de la Juventud Mexicana crearon dos nuevas organizaciones masculinas: la Unión de Católicos Mexicanos y la Juventud Católica Mexicana. La UDCM fue dividida en dos: la Unión Femenina Católica Mexicana (UfCM) y la Juventud Católica Femenina. La primera organizaría a las mujeres casadas, viudas y célibes de más de 35 años, mientras que la segunda supliría a las Vanguardias; es decir, se cohesionaría a las mujeres jóvenes y solteras de entre 15 y 34 años. La división de las organizaciones por edad y por género implicaba su sometimiento a la autoridad eclesiástica, misma que tendría que vigilar y modificar los discursos contestatarios de su militancia contra el régimen posrevolucionario.

Las cuatro asociaciones perdieron su autonomía e independencia frente al grupo de la jerarquía eclesiástica dominante que había pactado la paz. Mediante la creación de un Estatuto General de la Acción Católica se les obligó a modificar su estructura interna, acatando una legislación y un programa de trabajo general. Ésta fue la tercera trasformación que vivieron las Damas Católicas; sin embargo, el proceso de transición fue doblemente problemático pues implicó una sujeción muy estricta al Episcopado. Vivieron directamente la derrota y tuvieron que pagar las consecuencias de su apoyo al movimiento cristero, perdiendo la independencia que habían adquirido durante la guerra.

Bajo los estatutos generales de la ACM, las Damas modificaron una vez más el nombre de su organización, está vez sería un cambio definitivo. Recordando a Alfredo Méndez Medina, quien cuatro años antes había sugerido abandonar el nombre de "Damas", porque insinuaba que la organización únicamente aceptaba a gente acomodada, ${ }^{61}$ se retomó el nombre sugerido por su antiguo asesor y se convirtieron en Unión Femenina Católica Mexicana (UfCM). Años más tarde, recordaron este cambio como un acto de "sacrificio y obediencia" 62 a la jerarquía eclesiástica pues, después de casi veinte años de vida asociativa, perdieron su identidad pública y el nombre que defendieron durante su primer congreso, que les daba reconocimiento, las diferenciaba y las posicionaba públicamente como

${ }^{61}$ Hanson, The Day of Ideals..., p. 349.

${ }^{62}$ Informe que presenta la presidenta del Comité Central de la Primera Asamblea General de la Unión Femenina Católica de México, Acción Femenina, t. 1, n. 1, 1o. de enero de 1933, p. 13. 
representantes de la devoción, la piedad y el espíritu de caridad católica entre la sociedad.

En el reglamento de 1920 se estableció que las socias líderes se escogerían mediante una votación. En el nuevo reglamento de 1929 la presidenta de la UFCM debía ser nombrada directamente por el arzobispo de México, hecho que limitaba el poder de decisión y reducía el carácter democrático que daba sentido a su organización. También se restringieron sus actividades locales; como norma general, cada templo establecería un "grupo parroquial" por cada una de las cuatro organizaciones fundantes de la ACM. Estos "grupos" debían presentar un informe y donar parte de sus ingresos a los comités diocesanos. De esta forma cualquier desarrollo de la Acción Católica en edificios laicos o abiertos al público debía quedar bajo la supervisión del sacerdote local y entregar cuentas a la parroquia.

La Unión Femenina Católica de México no sería la excepción. Trabajaría "parroquialmente", lo que significaba que los sacerdotes locales tendrían que decidir qué acciones se llevarían a cabo entre su feligresía. Los nuevos "grupos parroquiales" correspondían a las actividades que las Damas realizaban en los templos de los distintos barrios y colonias de la ciudad de México, que les permitió cultivar vínculos de cohesión social y actuar como una "red de apoyo" durante los momentos de mayor persecución religiosa.

Estos grupos fueron concebidos por la UFCM como "el verdadero obrero de toda la organización", ${ }^{63}$ al encargarse de forjar vida comunitaria en los barrios y colonias circunscritas a cada parroquia. Organizaban actividades como kermeses, recaudaban fondos, fomentaban la devoción y promovían las prácticas religiosas, éstas eran sus actividades cotidianas entre niños, mujeres y hombres, que vivían alrededor de los templos y se realizaban en distintos espacios, ya fueran domicilios particulares, locales alquilados, entre otros. Este tipo de actividades eran constantes y cotidianas y habían quedado de lado para dar prioridad a acciones políticas. Por tanto, el interés de crear "grupos parroquiales" era hacer visible su importancia. Sin embargo, la organización "parroquial" era jerárquica y vertical y eliminó el contacto horizontal entre socias y templos, esto provocó que la mayoría de las actividades se volvieran acciones locales. ${ }^{64}$

63 “Organización”, UIA, BFXC, AHUFCM, primera asamblea general, caja 4, exp. 24, septiembre de 1932.

${ }^{64}$ Como eran el trabajo escolar, el trabajo catequístico, la propaganda, academias para madres, obreras y niñas, bibliotecas, buena prensa, círculos de estudio, confederación de instituciones regionales para adultos, cultura, dispensario, entronizaciones del Sagrado Co- 
Las socias se quejaban de la falta de preparación y comprensión, así como de la apatía de algunas afiliadas o bien, su oposición a la disciplina y falta de conocimiento de los estatutos de la ACM. Por ello, la única sección que se impuso fue la de "propaganda e instrucción de la práctica religiosa y devocional”, que abonaba al fortalecimiento de la doctrina católica y la influencia de la Iglesia entre la sociedad. Así, las Damas reafirmaron su carácter como una organización dedicada a fomentar la doctrina y los valores católicos en los distintos barrios y colonias.

Cada "grupo parroquial" tenía que registrarse como parte de la UFCM, mediante un documento denominado "acta parroquial"; se informaba al Comité Central los nombres de sus afiliadas y las actividades que se llevaban a cabo. Todas iban firmadas por el sacerdote local, quien decidía los trabajos cotidianos.

Las primeras actas que se recibieron fueron de los centros locales de las Damas más antiguos, como el de San Cosme, donde vivía la presidenta de la Unión, Elena Lascuráin. Este templo presentó su "acta" el día 15 de febrero de 1930, a mes y medio de la fundación de la ACM. ${ }^{65}$ Asimismo, la iglesia del Inmaculado Corazón de María, ubicada en la colonia Guerrero, muy cerca de la fábrica La Britania, que había sido un centro muy activo entre 1920 y 1926, presentó su adhesión en noviembre de $1929 .{ }^{66}$

En espacios más autónomos y beligerantes la transformación requirió del apoyo del padre Darío Miranda, quien fungió como asesor. Por ejemplo, Miranda tuvo que dar tres conferencias ante las Damas de Coyoacán para explicarles el objetivo y el funcionamiento de la nueva organización femenina. Es importante señalar que Coyoacán destacó durante la persecución religiosa por apoyar a los sacerdotes encarcelados con comida, ropa y dinero. ${ }^{67}$

Otras iglesias que fundaron sus comités entre 1930 y 1940 fueron: la del Sagrado Corazón de Jesús, de Santa Trinidad y Nuestra Señora del Refugio en la colonia Peralvillo, de San Miguel Arcángel, de Cristo Rey en la colonia

razón de Jesús y de la santísima virgen de Guadalupe, escuelas, moralidad y regeneración, patronatos, piedad, ropero para pobres y hospitales, seminario, socorros, periódicos a familias pobres y vergonzantes, visitas de hospitales y cárceles.

65 "Acta de fundación del Comité Parroquial de la Iglesia de San Cosme”, UiA, BfXC, Ahufcm, Correspondencia, Comités Parroquiales, caja 9, exp. 44, 15 de febrero de 1930.

66 "Acta de fundación del Comité Parroquial de la Iglesia del Inmaculado Corazón de María", UIA, BfXC, AHufcm, Correspondencia, Comités Parroquiales, caja 9, exp. 44, 29 de noviembre de 1929.

67 “Acta de fundación del Comité Parroquial de la Parroquia de Coyoacán”, uIA, BFXC, Ahufcm, Correspondencia, Comités Parroquiales, caja 9, exp. 44, 28 de febrero de 1930. 
Portales, de Santa Catarina Mártir, del Inmaculado Corazón de María, del Espíritu Santo, de San Jacinto ubicada en San Ángel y el santuario de María Inmaculada ${ }^{68}$ (véase el plano 3).

Hacia 1932, la UfCM de la ciudad de México contaba con un total de 400 socias, distribuidas en 30 grupos parroquiales, que trabajaban en torno de las entronizaciones, catecismos, seminario, cruzadas eucarísticas, ropero para pobres, enseñanza, bibliotecas, piedad, extensión, unión de madres, unión de obreras y sirvientas, escuelas, auxilios, propaganda, socorro perpetuo, apologética, prorregeneración, niños desamparados y hospitales, entre otras ${ }^{69}$ Las socias mantuvieron el interés de la organización por impulsar la educación religiosa entre niños, jóvenes y adultos, en particular entre mujeres trabajadoras. Asimismo, se interesaron en realizar actividades que desde su punto de vista formaban parte de las labores femeninas, por ejemplo, vestir a los niños pobres y atender a los enfermos, entre otras.

Tal y como se observa en el plano 3, en la década de 1930, la ciudad de México continuaba en constante crecimiento poblacional y urbano. Se comenzaron a perder los linderos que separaban a la ciudad con las municipalidades más cercanas, aspecto que comenzó a afectar la administración de los servicios públicos, y con ello, la vida urbana. A fin de evitar la superposición de autoridades locales se fundó el Departamento del Distrito Federal (DDF) en 1928, para centralizar los recursos y el gobierno en manos del presidente de la República, reducir los costos de la administración, unificar la infraestructura urbana, mejorar y garantizar la planificación y la regulación del desarrollo urbano. ${ }^{70}$

La fundación del DDF trajo como consecuencia la transformación de las municipalidades en delegaciones, acción que limitó el poder político de las administraciones locales, pues no podrían manejar sus propios recursos ni elegir a su personal judicial. La única figura con autoridad administrativa, hacendaria y política de la capital del país quedaría en manos de la figura del jefe del DDF, que actuó como representante del ejecutivo federal.

68 Idem.

69 "Comisiones", Acción Femenina, 1o. de enero de 1933, t. 1, n. 1, p. 24.

70 Sergio Miranda Pacheco, La creación del Departamento del Distrito Federal. Urbanización, política y cambio institucional, 1920-1934. México, Universidad Nacional Autónoma de México, Instituto de Investigaciones Históricas, 2008, 104 p. (Serie Historia Moderna y Contemporánea, 50). www.historicas.unam.mx/publicaciones/publicadigital/libros/creacion/ddf.html [consultado el 11 de febrero de 2020], p. 13-20. 
Este proceso provocó un cambio en la división territorial. Las antiguas municipalidades de México, Tacuba, Tacubaya y Mixcoac formarían el Departamento Central. Mientras que Guadalupe Hidalgo, Azcapotzalco, Iztacalco, General Anaya, Coyoacán, San Ángel, la Magdalena Contreras, Cuajimalpa, Tlalpan, Iztapalapa, Xochimilco, Milpa Alta y Tláhuac conformarían las delegaciones. ${ }^{71}$ Dos años después, en junio de 1931, se decidió suprimir el Departamento Central y establecer una nueva zona político-administrativa, que se volvió a denominar "Ciudad de México", y que se convirtió en la capital del país. Esta nueva zona anexaría a su territorio las delegaciones de Guadalupe Hidalgo y General Anaya ${ }^{72}$ (véase el plano 3).

Poco a poco, la UfCM fue adaptando su programa general a cada una de las colonias, barrios y necesidades locales; cada grupo adquirió formas distintas, sin perder de vista los servicios centrales "el perfeccionamiento cristiano, la instrucción religiosa, la elevación moral y el perfeccionamiento cultural y social". ${ }^{73}$ Por primera vez, la organización dio cuenta de todos los sitios urbanos donde mantenía algún tipo de representación. Gracias a estos registros se logra observar una presencia bien estructurada de la organización en la ciudad.

Conforme la ciudad expandió sus límites y se crearon nuevas colonias, la Unión Femenina Católica Mexicana también amplió sus espacios de acción, la organización promovió la construcción de nuevas parroquias, que permitieron ampliar sus ámbitos de acción y sus actividades, con lo que establecieron fuertes lazos de cohesión social entre los vecinos que fungieron como apoyo para la Iglesia.

Ante el desborde de los límites de la ciudad, el trabajo parroquial permitió a la UFCM actuar de manera acotada sobre su espacio más inmediato: el trabajo en los barrios y las colonias a las que se circunscribía cada templo. Hacia el oeste y noroeste de la ciudad, como Azcapotzalco, Tacubaya, Peralvillo y Valle Gómez, se asentaron los enclaves industriales más importantes, en esta misma zona las socias mantuvieron su presencia, pues llevaban varios años trabajando ahí y contaban con el reconocimiento de la comunidad. Asimismo, continuaron actuando en el barrio de la Merced y la colonia Guerrero.

${ }^{71}$ Miranda, La creación del Departamento del Distrito Federal..., p. 62.

${ }^{72}$ Miranda, La creación del Departamento del Distrito Federal..., p. 64.

73 “Organización”, UIA, BFXC, AHUFCM, primera asamblea general, caja 4, exp. 24, septiembre de 1932. 
Hacia el sur se desarrolló el sector habitacional. Se crearon fraccionamientos hacia la Doctores, Portales, General Anaya, Coyoacán, Iztapalapa, San Ángel y Tlalpan. Las Damas expandieron sus actividades hacia estas zonas habitadas por personas de medianos recursos $;^{74}$ en estos espacios pudieron consolidar sus actividades en torno de la catequesis, las entronizaciones y la propaganda religiosa.

De esta forma, su programa se ajustó a las nuevas condiciones impuestas por los Arreglos de 1929. La UFCM se planteó nuevas dinámicas y formas de trabajo que marcaron sus actividades en los años venideros, sin perder de vista tres elementos centrales de su programa social: la instrucción religiosa, la acción educativa y la moralización de la población. Así, durante más de veinte años las Damas Católicas lograron acumular una serie de experiencias que les permitió posicionarse espacialmente en torno de los templos locales para construir redes y lazos de sociabilidad entre vecinos. Esta experiencia fue retomada por la UFCM, que se dedicaría a fomentar un discurso homogéneo, claro, preciso y aprobado por la alta jerarquía eclesiástica, de la devoción religiosa, de la importancia de la religión en la educación primaria y del papel de la moral católica como guía para la sociedad mexicana.

\section{Conclusiones}

A lo largo de su historia las Damas Católicas demostraron una enorme capacidad de adaptación y movilidad, mismas que les permitieron sobrevivir, recomponerse y reestructurarse en varios momentos. Las socias cambiaron su forma de actuar y fueron afinando su trabajo. Frente a la imposición de una serie de medidas anticlericales que daban sentido al estado posrevolucionario sus actividades comenzaron a adquirir tonalidades cada vez más políticas y beligerantes. A la par su acción se fue profesionalizando, desarrollaron una identidad propia y un programa social que profesaba un lenguaje y un marco ideológico basado en exaltar el papel de la mujer. Crearon un programa que les abrió las puertas de la vida pública y desde ahí promovieron el papel tradicional de la mujer como madre y esposa dedicada al hogar, protectora y cuidadora de la familia, de los valores morales y re-

${ }^{74}$ Emma Cecilia Barraza Gómez, En las entrañas de la urbe: política, patrimonio y planeación en la ciudad de México (1940-1980). Una historia desde sus debates, tesis para obtener el grado de maestría en Historia, México, Universidad Nacional Autónoma de México, 2014, p. 21. 
ligiosos. Este discurso les permitió encontrar un campo de acción al interior de la militancia católica exclusivo para ellas, desde ahí lograron abrirse nuevos caminos, desenvolverse en nuevos escenarios, actuar políticamente y convertirse en figuras públicas.

En 1920 dejaron de ser una organización dedicada a satisfacer las demandas regionales para convertirse en una confederación con la fuerza suficiente de actuar a nivel nacional, promover un discurso y una acción social capaz de hacer frente al anticlericalismo estatal. Esto les permitió crear centros educativos para niños y obreras que se convertirían en espacios laicos de recreación del catolicismo, es decir, lograron llevar su acción más allá de la estructura parroquial y actuar de manera autónoma, siempre bajo las premisas morales de la Iglesia.

La labor de las Damas no puede menospreciarse; al contrario, con aquellas actividades que nacieron de un interés caritativo y filantrópico, con el paso de los años su organización demostró una enorme capacidad de adaptación a los aconteceres políticos y sociales que fueron mermando el papel de la Iglesia en la vida pública y privada de los habitantes de la ciudad de México. Sus acciones se fueron convirtiendo en una serie de actos de resistencia política, que marcaron la participación pública de las mujeres católicas. Lograron dialogar con su contexto, trasformar sus actividades y superar eficazmente las dificultades a las que se enfrentaron durante las guerras, persecuciones religiosas y crisis políticas que les tocó vivir. Esta cualidad les permitió restablecerse en más de una ocasión, reorganizarse y recobrar su número de socias, así como ajustar su programa de trabajo a los nuevos tiempos y priorizar aquellas actividades que les parecían esenciales para la vida social de la nación, como fue el catecismo, que siempre estuvo presente y que conforme nos acercamos a la década de los años treinta se convirtió en el centro de su organización.

La ciudad de México fue su laboratorio, su centro de operaciones y su zona de resguardo. En este espacio, las Damas desarrollaron su programa en zonas clave como el centro y los barrios marginales del noreste de la capital; sin embargo, su acción permeó por toda la ciudad, lo cual les permitió crear lazos de sociabilidad y solidaridad entre católicos. Las Damas actuaron en una ciudad en movimiento y constante transformación. Sobre la capital convergían distintas formas de poder y diversas formas de gobierno; ésta se transformó en un espacio de pugna constante, entre la Iglesia y el Estado. Las Damas Católicas se convirtieron en una nueva forma de participación ciudadana cuya fuerza política se encaminó a generar notoriedad 
pública de las devociones y prácticas religiosas. Sus acciones en el espacio urbano fueron un acto de beligerancia y resistencia frente a las políticas anticlericales del Estado posrevolucionario.

Entre 1912 y 1930, mantuvieron activa la participación comunitaria, así como la administración de servicios públicos dirigidos a los pobres y menesterosos, creando espacios educativos, dirigidos al fomento del catecismo y de la fe. Queda pendiente para futuras investigaciones analizar cómo este modelo se fue trasformando a partir de 1930, cuáles fueron sus nuevas características, cómo se mantuvo y en qué momento cesó, o si, por el contrario, continua vigente la UFCM.

\section{Fuentes}

Siglas o archivos

AGN Archivo General de la Nación

aham Archivo Histórico del Arzobispado de México

AACM Archivo de la Acción Católica Mexicana

AHUfCM Archivo Histórico de la Unión Femenina Católica Mexicana

BFXC Biblioteca Francisco Xavier Clavigero

Cenm Centro de Estudios de Historia de México, Fundación Carlos Slim

DGIPS Dirección General de Investigaciones Políticas y Sociales

UIA Universidad Iberoamericana

LNDLR Liga Nacional Defensora de la Libertad Religiosa

PCN Partido Católico Nacional

UFCM Unión Femenina Católica Mexicana

\section{HEMEROGRAFÍA}

Acción Femenina (1933-1937), ciudad de México.

El Universal (1919-1922), ciudad de México.

Excélsior (1920-1921), ciudad de México.

La Dama Católica. Órgano de difusión de la Unión de Damas Católicas Mejicanas (1920-1926), ciudad de México.

La Mujer Católica Mexicana. Órgano de la Confederación Nacional de Damas Católicas (1914), ciudad de México. 
Bibliografía

Aguirre Cristiani, María Gabriela, ¿Una historia compartida? Revolución Mexicana y catolicismo social, 1913-1924, México, Instituto Mexicano de Doctrina Social Cristiana/Instituto Tecnológico Autónomo de México/Universidad Autónoma Metropolitana, 2008.

Altamirano, Graziella, Pedro Lascuráin: un hombre en la encrucijada de la Revolución, México, Instituto de Investigaciones Dr. José María Luis Mora, 2004.

Aréchiga Córdoba, Ernesto, Tepito: del antiguo barrio de indios al arrabal. 18681929. Una historia de una urbanización inacabada, México, ¡UníoS! (Unidad Obrera y Socialista), 2003.

Arrom, Silvia, Volunteering for a Cause: Gender, Faith, and Charity in Mexico from the Reform to the Revolution, New Mexico, University of New Mexico Press, 2016.

Aspe Armella, María Luisa, La formación social y política de los católicos mexicanos, México, Universidad Iberoamericana, 2013.

Ávila Espinosa, Felipe Arturo, "Organizaciones, influencias y luchas de los trabajadores durante el régimen maderista”, Estudios de Historia Moderna y Contemporánea de México, n. 18, 1998, p. 121-170.

"Una renovada misión: las organizaciones católicas de trabajadores entre 1906 y 1911", Estudios de Historia Moderna y Contemporánea de México, n. 27, 2004, p. 61-94.

Bantues, Adrian A., "Mexican Revolutionary Anticlericalism: Concepts and Typologies", The Americas, v. 65, n. 4, 2009, p. 467-480.

Barraza Gómez, Emma Cecilia, En las entrañas de la urbe: política, patrimonio y planeación en la Ciudad de México (1940-1980). Una historia desde sus debates, tesis para obtener el grado de maestría en Historia, México, Universidad Nacional Autónoma de México, 2014.

Bautista García, Cecilia, La disyuntiva del Estado y de la Iglesia en la consolidación del orden liberal: México, 1856-1910, México, El Colegio de México, Centro de Estudios Históricos/Fideicomiso Historia de las Américas/Universidad Michoacana de San Nicolás de Hidalgo, 2012.

Blancarte, Roberto, "Closing Comment: 'Personal Enemies of God': Anticlericals and Anticlericalism in Revolutionary Mexico, 1915-1940”, The Americas, v. 65, n. 4, 2009, p. 589-599.

BuIss, Katherine Elaine, "Theater of Operations: Reform, Politics, and the Battle for Prostitutes' Redemption at Revolutionary Mexico City's Syphilis Hospital", en Stephanie Mitchell y Patience Schell (eds.), The Women's Revolution in Mexico, 1910-1953, Lanham, Rowman and Littlefield, 2007, p. 125-148. 
Boylan, Kristina A., Mexican Catholic Women's Activism, 1929-1940, tesis para obtener el grado de doctor en Filosofía, Londres, Universidad de Oxford, 2000. , “Género, fe y nación. El activismo de las católicas mexicanas, 1917-1940", en Gabriela Cano, Jocelyn Olcott y Mary Kay Vaughan (comps.), Género, poder y política en el México posrevolucionario, México, Fondo de Cultura Económica, 2009.

Bracamonte, Lucía, "Catolicismo y condición femenina: representaciones de género sobre la maternidad y la domesticidad en la prensa del suroeste bonaerense argentino a principios del siglo xx”, Secuencia, n. 88, 2014, p. 88-108.

Butler, Matthew, “Sotanas rojinegras: Catholic Anticlericalism and México's Revolutionary Schism”, The Americas, v. 65, n. 4, 2009, p. 535-558.

“'Su hija Inés': católicas laicas, el obispo Luis María Martínez y el conflicto religioso michoacano, 1927-1929”, Historia Mexicana, El Colegio de México, México, v. LXVII, n. 3, 2018, p. 1249-1293.

Chaoul Pereyra, María Eugenia, Entre la esperanza de cambio y la continuidad de la vida. El espacio de las escuelas primarias nacionales en la ciudad de México 1891-1919, México, Instituto de Investigaciones Dr. José María Luis Mora, 2014. Collado Herrera, María del Carmen, La burguesía mexicana: el emporio Braniff y su participación política, 1865-1920, México, Siglo XXI, 1987.

"Los sonorenses en la capital”, en María del Carmen Collado Herrera (coord.), Miradas recurrentes I. La ciudad de México en los siglos XIX y XX, México, Instituto de Investigaciones Dr. José María Luis Mora, 2004, p. 102-130.

Dawes, Helena, "The Catholic Church and the Woman Question: Catholic Feminism in Italy in the Early 1900s”, The Catholic Historical Review, v. 97, n. 3, 2011, p. 486-526.

EspinosA, David, "Restoring Christian Social Order. The Mexican Catholic Youth Association (1913-1932)”, The Americas, v. 59, n. 4, 2003, p. 451-474.

Giorgio, Michaela de, "El modelo católico", en Georges Duby y Michell Perrot, Historia de las mujeres. 4. El siglo XIX, Barcelona, Taurus, 1993, p. 183-218.

Hanson, Randall S., The Day of Ideals: Catholic Social Action in the Age of the Mexican Revolution, 1867-1929, tesis para obtener el grado de doctor en Filosofía, Indiana, Universidad de Indiana, Departamento de Historia, 1994.

LaVrin, Asunción, Women, Feminism and Social Change in Argentina, Chile and Uruguay (1890-1940), Lincoln, University of Nebraska Press, 1995.

LEAR, John, "Del mutualismo a la resistencia: las organizaciones laborales en la ciudad de México de fin del Porfiriato a la Revolución”, en Carlos Illades y Ariel Rodríguez Kuri (comps.), Ciudad de México: instituciones, actores sociales y conflicto político 1774-1931, México, El Colegio de Michoacán/Universidad Autónoma Metropolitana, 1996, p. 275-308. 
Llona GonzÁlez, Mirén, "El feminismo católico en los años veinte y sus antecedentes ideológicos”, Vasconia, n. 25, 1998, p. 283-299.

Machen, Emily, "Global Fight for Faith: Catholic International Religious Outreach in Turn-of-the-Century France”, Catholic Historical Review, v. 100, n. 2, 2014, p. 292-318.

MÁrquez Morfín, Lourdes, La desigualdad ante la muerte en la ciudad de México. El tifo y el cólera (1813-1833), México, Siglo XXI, 1994.

Martínez Mesa, Francisco, De profanos a devotos: la enseñanza elemental católica en la ciudad de México, 1891-1910, tesis de licenciatura en Historia, México, Instituto de Investigaciones Dr. José María Luis Mora, 2015.

Miranda Pacheco, Sergio, La creación del Departamento del Distrito Federal. Urbanización, política y cambio institucional, 1920-1934, México, Universidad Nacional Autónoma de México, Instituto de Investigaciones Históricas, 2008, 103 p. (Serie Historia Moderna y Contemporánea, 50). www.historicas.unam.mx/ publicaciones/publicadigital/libros/creacion/ddf.html [consultado el 11 de febrero de 2020].

Moreno ChÁvez, José Alberto, Devociones políticas. Cultura católica y politización en la arquidiócesis de México 1880-1920, México, El Colegio de México, 2013.

"Visiones del apocalipsis: violencia e imaginarios católicos en el México Revolucionario”, en Laura Rojas y Susana Deeds (eds.), México a la luz de sus revoluciones, México, El Colegio de México, 2014, v. 2, p. 315-349.

NARI, Marcela, "El feminismo frente a la cuestión de la mujer en las primeras décadas del siglo xx", en Juan Suriano (comp.), La cuestión social en Argentina, 1870-1943, Buenos Aires, La Colmena, 2000.

O’Dogherty Madrazo, Laura, "Restaurarlo todo en Cristo: Unión de Damas Católicas Mejicanas, 1920-1926”, Estudios de Historia Moderna y Contemporánea de México, v. 14, 1991, p. 129-158.

De urnas y sotanas. El Partido Católico Nacional en Jalisco, México, Consejo Nacional para la Culturas y las Artes, 2001.

"La Iglesia Católica frente al liberalismo", en Erika Pani (coord.), Conservadurismo y derechas en la historia de México, México, Fondo de Cultura Económica/Consejo Nacional para la Culturas y las Artes, 2009, t. 1, p. 363-391.

Padilla Rangel, Yolanda, Después de la tempestad. La reorganización católica en Aguascalientes, México, El Colegio de Michoacán/Universidad Autónoma de Aguascalientes, 2001.

Rodríguez Kuri, Ariel, “Desabasto, hambre y respuesta política, 1915”, en Carlos Illades y Ariel Rodríguez Kuri (comps.), Instituciones y ciudad. Ocho estudios históricos sobre la ciudad de México, México, ¡UníoS!, 2000, p. 133-166. 
SÁnchez Santiró, Ernest, "El nuevo orden parroquial de la ciudad de México: población, étnica y territorio (1768-1777)”, Estudios de Historia Novohispana, n. 30, 2004, p. 63-92.

Schell, Patience, Church and State Education in Revolutionary Mexico City, Tucson, Universidad de Arizona, 2003. , "An Honorable Avocation for Ladies: The Work of the Mexico City Unión de Damas Católicas Mexicanas, 1912-1926”, Journal of Women's History, v. 4, n. 4, 1999, p. 78-103.

Silva de la Rosa, Ana Patricia, Los Caballeros de Colón y su participación en el conflicto religioso de 1926 a 1929, tesis que para obtener el título de licenciado en Historia, México, Universidad Nacional Autónoma de México, Facultad de Filosofía y Letras, 2004.

Vivaldo Martínez, Juan Pablo, La Unión de Damas Católicas Mexicanas 1912-1929. Una historia política, tesis para obtener el grado de maestro en Historia, México, Universidad Autónoma Metropolitana, 2011.

Zavacké, Marina, "Crossing Sisters: Patterns of Protest in the Journal of the Catholic Union of Slovak Women during the Second World War", Social History, v. 37, n. 4,2012 , p. $425-451$. 


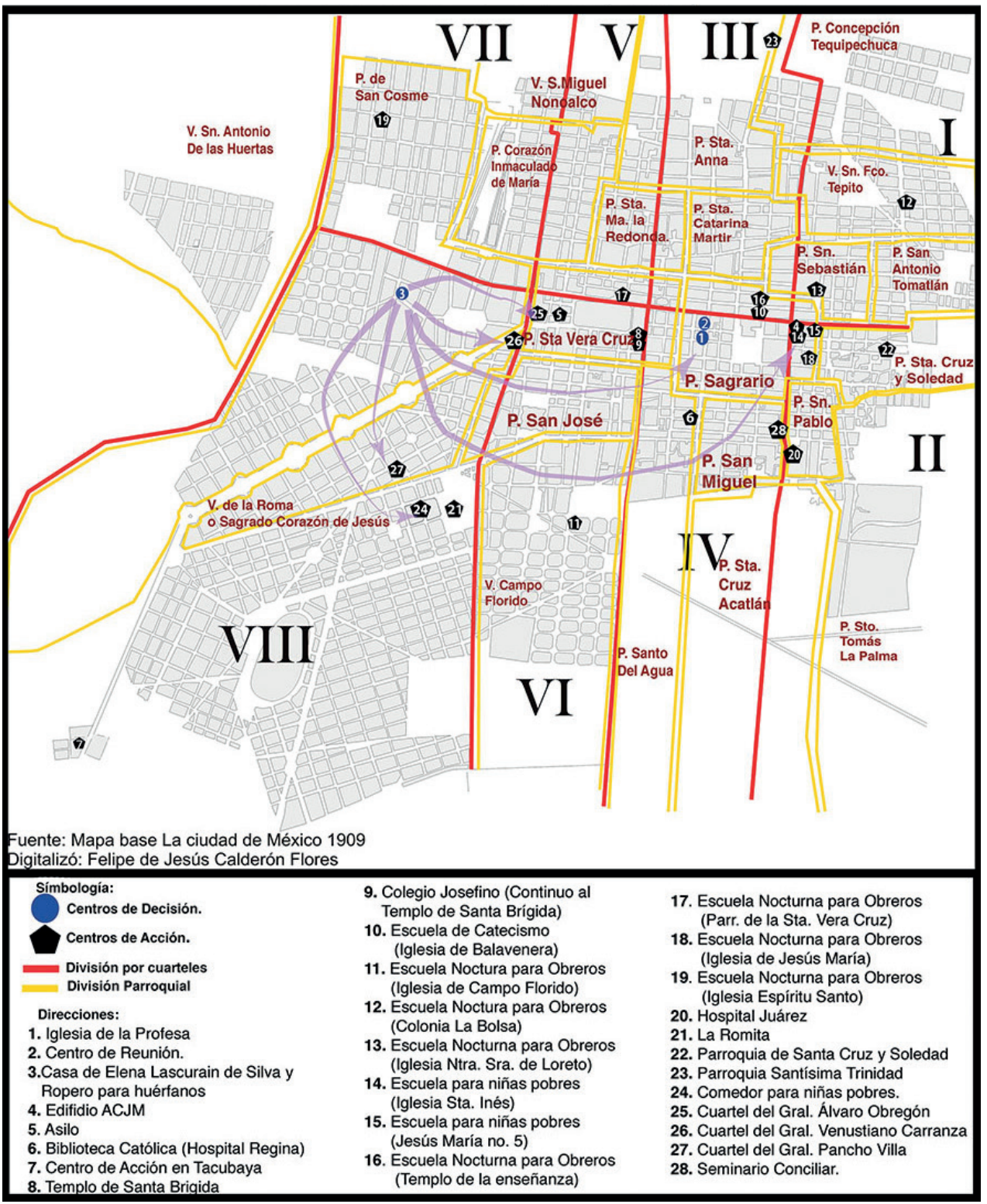




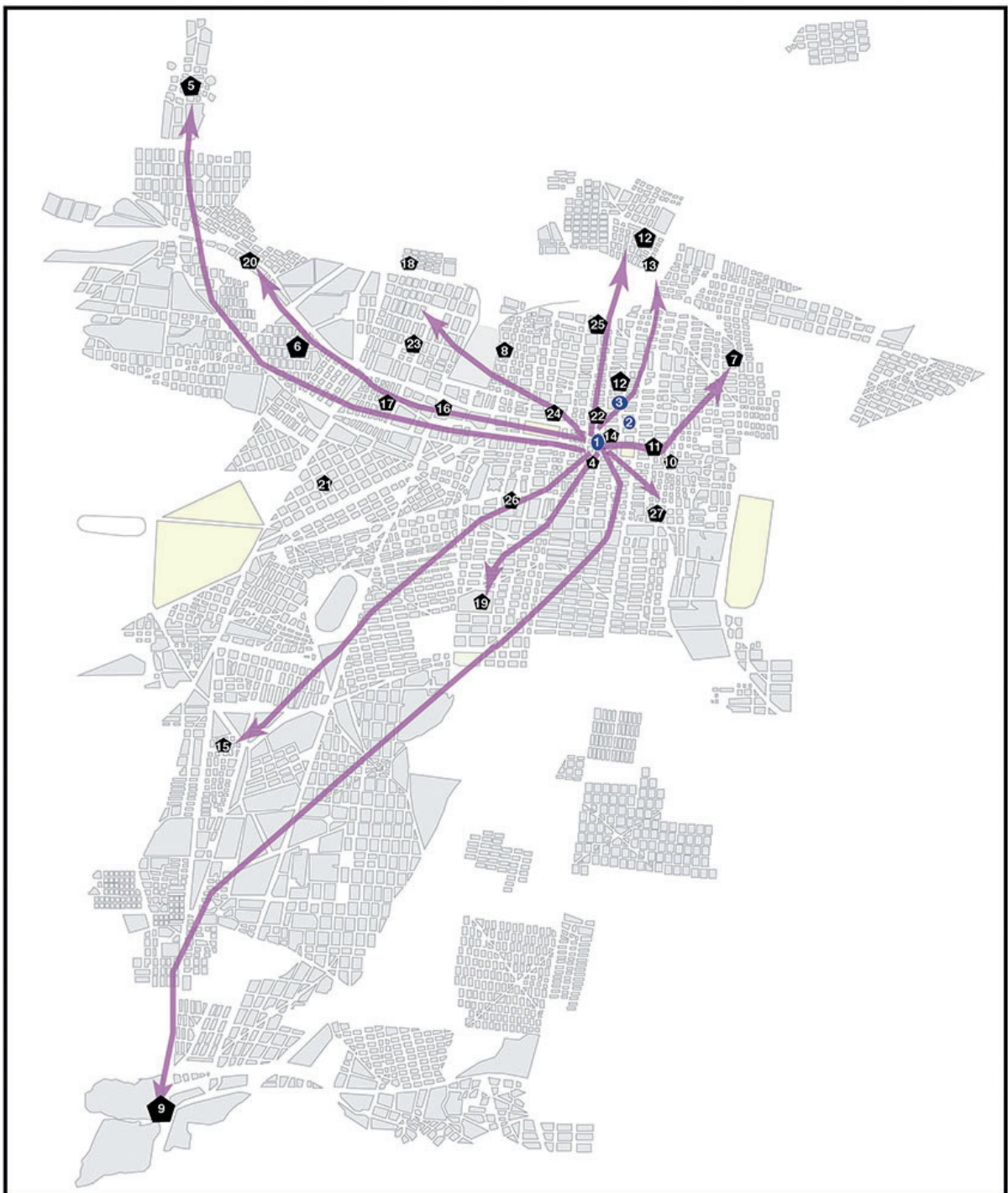

1. Iglesia La Profesa

2.Primera Sede UDCM

3.Segunda Sede UDCM

4.Sede Caballeros de Colón.

5. Escuela Católica Reforma.

6. Casa del Papelero

7. Escuela Granja

8. Escuela Sor Juana (Fábrica Britania)

9. Colegios San Ángel

10.Colegio Jesús María

11.Colegio San Felipe de Jesús
12. Colegio Sagrado Corazón de Jesús.

13. Fábrica La Esperanza (Peralvillo)

14. Academia Sección del Trabajo

15. Col. para Obreros.

16. Fábrica Tabacalera

17. Fábrica Larín

18. Fábrica de Velas La Moderna

19. Hospital General

20. Damas Popotla

21. Damas Cuauhtémoc

22. Teatro Esperanza Iris
23. Ejército de Defensa de la Mujer 24. Hospital Morelos

25. Prisión de Santiago Tlatelolco

26. Prisión de Belén

27. Hospital Juárez

28.Fábrica Pasamanería Francesa

Símbología:

Centros de Decisión.

Centros de Acción. 
Plano 3. Los Centros de la Unión Femenina Católica Mexicana (1930-1940)

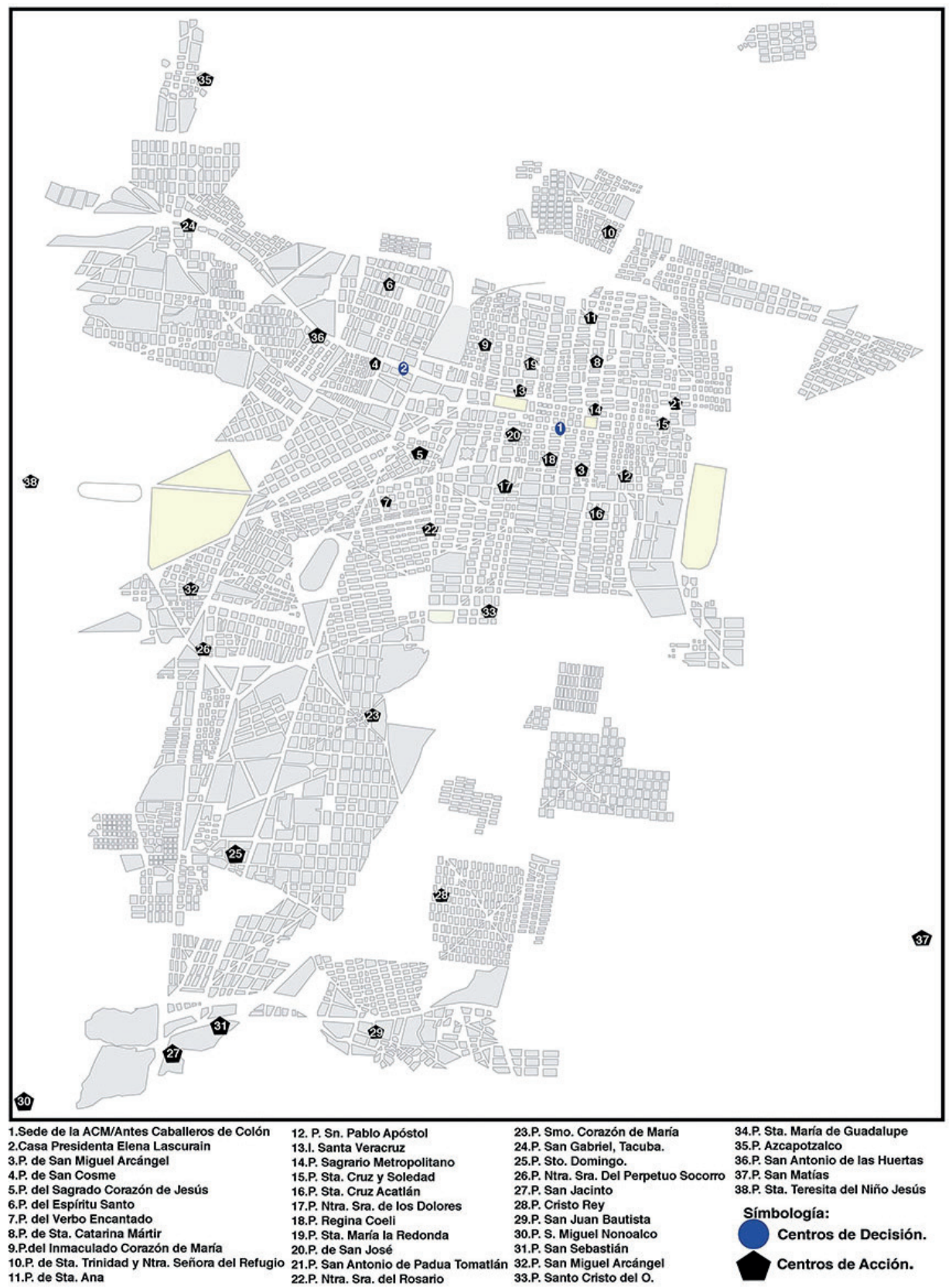


